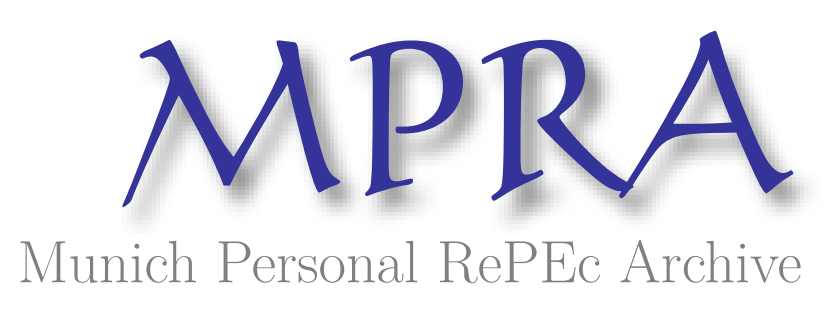

\title{
Zero Pricing Platform Competition
}

Shekhar, Shiva

March 2020

Online at https://mpra.ub.uni-muenchen.de/99364/

MPRA Paper No. 99364, posted 07 Apr 2020 16:40 UTC 


\title{
Zero pricing platform competition
}

\author{
Shiva Shekhar*
}

March 2020

\begin{abstract}
This article studies competition between different types of ad-funded platforms attracting consumers with free services. Consumers often find advertisements a nuisance on such platforms. We study how under a competitive setting platforms balance the tension between attracting consumers and rent extraction from the advertising side. We propose a flexible yet simple model that studies competition between standard platforms and social media platforms (with same-side network effects). We find that an increase in either positive same-side network effects or an increase in consumer disutility from advertisements leads to a reduction in the number of ads on that platform. When competing platforms merge, consumer side network effects do not impact prices and the number of ads is higher. In a setting where consumers present a negative (congestion) externality on each other, competition fails to protect consumer welfare and behaves erratically. Finally, we present a few extensions and discuss some policy implications.
\end{abstract}

JEL Classification: L13, L22, L86, K21.

Keywords: Social media platforms, platforms, two-sided markets, same side network effects, cross side network effects, advertising.

*Compass Lexecon, Square de Meeus 23, Brussels, Belgium. email: shiva.shekhar.g@gmail.com. This is an independent piece of research and is not necessarily the view of Compass Lexecon.

We thank Leonardo Madio for his insightful comments. 


\section{Introduction}

Platforms funded by advertisements are becoming an increasingly important part of the digital ecosystem. The services offered by such platforms are highly valued by consumers. ${ }^{1}$ These platforms compete for consumer attention as the value of such consumers is the willingness to pay for access to such consumers by advertisements. ${ }^{2}$ Google and Facebook are largest such platforms adopting such a business model. These platforms are unanimously considered dominant and competition between such platforms is a hotly debated topic in both academic and policy-making circles. ${ }^{3}$ The zero pricing business model of such platforms presents a particular challenge for anti-trust authorities to quantify effects on consumers and welfare. ${ }^{4}$ The tools available to competition authorities to quantify impact of a merger on competition are based on a consumer facing price. ${ }^{5}$ The "zeroness" of the prices makes it hard to do so while also suggesting the platforms have evolved and perhaps compete for consumers in other dimensions. ${ }^{6}$

These platforms seek to attract consumers by offering the platform services or content for free and earn through charging advertisers to access consumers. Advertisements on a platform are often considered a nuisance by consumers and impact the quality of services on a platform. ${ }^{7}$ There is a tension between the network effects in play in such multi-sided markets. On the one hand, advertisers value positively the interactions of consumers on a platform, on the other hand, consumers negatively value advertisements on such platforms. There is a stream of arguments that imply that competition in such markets might help regulate the intensity of advertisements. ${ }^{8}$ Similarly, there is another stream that discusses consumer privacy as a dimension of competition. ${ }^{9}$

The CMA in its recent market study on advertisement funded platforms identified two types of platforms. The first being a standard platform which offers platform services to consumers while placing advertisements within its content. Examples of such platforms include search platforms, video streaming platforms like Youtube, Vimeo and Dailymotion. The second type of platform is a social media platform where consumers join to interact, share and discover engaging content. These markets apart from offering content also include the presence of

\footnotetext{
${ }^{1}$ See Brynjolfsson et al. (2019) for a detailed review on how consumers value such online services.

${ }^{2}$ See Digital Platforms Inquiry: Final Report, 2019 (2019) which suggests that the average advertising revenue per user was 116.3 Australian Dollars for Google search and 72.8 Australian Dollars for Facebook in 2018.

${ }^{3}$ The Competition and Markets Authority (CMA) has released an interim report discussing ad-funded platforms. A similar discussion can be found in the "Digital platforms inquiry: Final report" published by the Australian Competition and Consumer Commission (ACCC). Similarly, the Stigler report (Scott Morton et al. (2019)) also discusses importance of such platforms. These reports concur that Facebook and Google are dominant.

${ }^{4}$ The Bundeskartellamt (2019) points out that "Free" is not a special zone where Economics or anti-trust does not apply. A free good is one where the seller has chosen to set a monetary price of zero and may set other, non-monetary conditions or duties.

${ }^{5}$ See Evans (2011) for a detailed analysis on how some of the tools breakdown under zero prices.

${ }^{6}$ OECD $(2018 a)$ states that "...just because a firm is constrained in terms of the prices it can charge to a singleoption (zero) does not mean that it would not have the ability to affect unilaterally the terms of exchanges with consumers to its benefits, and to consumers' detriment", pg. 14.

${ }^{7}$ See Digital platforms interim report (2019) by CMA.

${ }^{8}$ OECD (2018a) suggests advertising intensity as a competitive tool. See para 61 .

${ }^{9}$ See Esayas (2018) that also point out that both European Commission and the Federal Trade Commission have acknowledge data privacy to be a non-price attribute of competition. Also, See EC Case M.8124Microsoft/LinkedIn. European Commission Decision C(2016)8404, 2016 (2019) case.
} 
another type of network effect through which they attract consumers. This network effect is the same side network effect due to interaction with other consumers. ${ }^{10}{ }^{11}$

In this paper, we try to understand how competition functions under the business model of "zero" consumer facing prices used by such platforms. We employ a tractable yet very flexible model that allows us to understand competition between the different types of platforms. This model allows us to seamlessly switch between two types of such platforms: a standard platform which offers content or services to consumers and a social medial platform where same-side network effects play a role. In a competitive setting, the interaction of these network effects reveals interesting insights. We look at three types of competitive settings, firstly, competition between two standard platforms, secondly, competition between two social media platforms and finally, competition between a social media platform and a standard platform.

We confirm that advertising intensity can be used as a competitive tool by firms to attract consumers on a platform. ${ }^{12}$ This can be observed through the pricing response of platforms. A unilateral increase in advertising prices at a platform, reduces advertising demand at that platform. This makes it relatively more attractive for consumers and results in consumer migration away from the rival platform. This in turn entails a negative impact on the advertising demand at the rival platform. We denote this as the "negative advertising externality". The rival platform responds by increasing its advertising price to attract consumers. As competition for consumers gets fiercer, platforms experience an upward pricing pressure on their advertising prices. Thus, we reveal an indirect channel of competition between platforms to attract consumers. We find that an increase in consumer disutility for advertisements or an increase in same-side network effects leads to higher advertising prices. Moreover, in comparison to a setting where two standard platform compete, competition (for consumers) between two social-media platforms is fiercer. This is evidenced by a higher advertising price in the latter competitive setting.

The impact of mergers between such platforms has become an important topic of discussion in both academic, policymaking and the political circles. ${ }^{13}$ Therefore, we try to understand how a merger between competing advertising funded platforms impacts competition. Specifically, how consumers are impacted in markets and what competitive channels are shut off post-merger. We find that a merger between either two competing standard platforms or two social media platforms makes platform advertising price indifferent to consumer disutility from advertisements or same-side network effect. The intuition is that the merged entity internalizes the "negative advertising externality" on its rival due to an increase in its price. This paints a stark picture of a merger outcome for consumers. These dominant platforms provide extremely valuable services and consumers might not have other credible outside options and can be exploited easily. We also discuss potential remedies whereby the competition regulator can put

\footnotetext{
${ }^{10}$ The Bundeskartellamt in the Facebook (2019) decision described such platforms as "It can be assumed that there is a specific demand for social networks, which is fundamentally different from the demand for other social media. The key purpose of social networks in finding and network with people the users already know, and to exchange on a daily basis experiences, opinions and contents among specific contacts which the users define based on identity."

${ }^{11}$ Also, see Online platforms and digital advertising Market study: interim report, 2019 (2019) that discusses the presence of both same-side and cross-side network effects on social media platforms.

${ }^{12}$ See OECD (2018a) pg, 15 for a discussion on it.

${ }^{13}$ See Argentesi, Buccirossi, Calvano, Duso, Marrazzo \& Nava (2019), Gautier \& Lamesch (2020), Ex-post Assessment of Merger Control Decisions in Digital Markets, 2019 (n.d.) and Digital Platforms Inquiry: Final Report, 2019 (2019).
} 
caps on advertisements and (reasonable) data extraction limits. We then discuss its impact on welfare, consumers and advertisers.

We present multiple extensions to the paper that illustrate the flexibility of the model. In particular, the case of consumer congestion externality is considered where consumers value negatively the presence of one another. We find that competition fails to protect consumer interest and, in some cases, ( when consumers value advertisements positively) leads to a fall in welfare on both the sides of the market. This is because platform try to divert the marginal consumer away from that platform. In the case when consumers positively value advertisement, a platform reduces its relative attractiveness for the marginal consumer by reducing the mass of (positively valued) advertisements. By doing so, consumers are worse-off as well as advertising firms. This presents a unique case where a merger to monopoly would results in an increase in consumer welfare and advertising side welfare. Finally, we look at the case of multi-homing consumers.

The paper is organized as follows. Section 2 discusses the relevant literature and our contributions to it. Section 3 introduces the model and the analysis is presented in section 4 . Section 5 discusses a setting where competing platforms merger and section 6 discusses the extensions. We conclude with section 7 .

\section{Related Literature}

The paper is related to the two-sided literature where seminal works include Armstrong (2006), Rochet \& Tirole (2003), Rochet \& Tirole (2006). We assume a competitive bottleneck where consumers single-home (see Armstrong (2006)) where a platform is a bottleneck for access to consumers by advertisers where consumers are offered platform service/content for "free" and platforms charge an advertising prices.

We also add to the discussion on competition in advertising funded platforms where consumer facing price is not a competitive parameter. There has been a vast literature on advertising funded TV and newspaper networks. The choice of content is discussed in Steiner (1952), Beebe (1977) which adds competition to the Steiner (1952) model and Spence \& Owen (1977) which also looks at competition. There exists a strand of literature that models consumers as finding advertisements a nuisance and is an implicit price paid by consumers (see Wilbur (2008), Anderson \& Gabszewicz (2006), Crampes et al. (2009), Huang et al. (2018)). Recent literature on zero pricing platforms includes Anderson \& Jullien (2015), Anderson \& Peitz (2020) and Calvano \& Polo (2020). We add to this literature by looking advertising as an implicit price paid by consumers. We try to understand how competition behaves in a model where cross-side negative externality interacts with same-side effects (where consumers value or dislike other consumers). We also add to the two-sided literature by proposing a simple yet very flexible model that allows seamless transition between different competitive settings. One is able to study a multitude of competitive settings where competition is between social-media platforms, between content/service provision platforms and between asymmetric platforms. Using indicator functions, one is able to easily switch between regimes and understand the indirect competitive links between platforms. This model also complements the interesting literature on two-sided markets with same-side network effects and cross-side network effects such as Belleflamme \& Peitz (2019b) and Angelini et al. (2019). We include negative same-side network effects which can be used a proxy for competition between agents.

We also add to the discussion on mergers in digital platforms. There has been a lot of atten- 
tion on mergers in digital markets and the associated impact on consumers and data protection. Recent works include Stucke \& Grunes (2015), Waehrer (2016), Argentesi, Buccirossi, Calvano, Duso, Marrazzio \& Nava (2019), Prat \& Valletti (2019), Gautier \& Lamesch (2020), Motta \& Peitz (2020). We look at the impact of a horizontal merger by two platforms and how their pricing incentives and strategies change. We find that post-merger advertising intensity rises and hurts consumer surplus. We present a stark picture where post-merger consumer preferences are ignored by platforms in favor of increasing platform profits. We find that consumers might experience significant harm due to the indispensability of the platforms and change in platform incentives in favor of advertising firms.

\section{The Model}

We model competition between two platforms in a differentiated setting with platforms denoted by $i \in\{1,2\}$ from the perspective of consumers. These platforms provide "free" services to consumers and follow an ad-based business model. In other words, they cater users' eyeballs to advertisers, which pay an ad price. However, consumers find advertisement a nuisance and platforms set advertising prices which control the level of advertisements. These platforms set advertising price to balance the consumer attraction with rent extraction to maximize profits.

Consumers. Consumers are continuously distributed according to their preferences where $s$ denotes the measure of the relative consumer preference for platform 2 against 1 . These preferences are distributed according to a cumulative density function $F(\cdot)$ with density $f(\cdot)$ which is symmetric around 0 in the interval $s \in\{\underline{s}, \bar{s}\}$, with $\underline{s}=-\bar{s}<0$. Hereafter, we refer to ' $s$ ' as the consumer type.

Consumers obtain access to platform services for free and platforms are funded by advertisements which are considered a nuisance by consumers. When consumers affiliate with a given platform, they obtain a value $(v)$ independent of network externalities. They value interactions with other consumers on a platform denoted by the marginal gain $\theta$ per consumer affiliated with the platform. Consumers obtain a disutility from advertisements on a platform which is denoted by a negative externality from the presence of advertisers $(\gamma)$ on the platform. ${ }^{14}$

It is important to point out that in such platforms, consumers access the platform for "free". Consumers indirectly compensate a platform through their presence and the discomfort of advertisements. The platform leverages its consumers base to charge a price to advertisers for access to those consumers.

The total utility of a type- $s$ consumer from joining the merged platform 1 in market is:

$$
u_{1}=v+g_{1} \cdot \theta \mathbf{E} D_{1}-\gamma A_{1}-s / 2
$$

where $g_{1}=1(0)$ takes a unit value if platform 1 is a ad-funded platform with same side network effect, else it takes a value of 0 . We denote by $A_{1}$ the number of advertisers active on the platform 1 by $\mathbf{E} D_{1}$ the consumer belief on the total mass of consumers affiliating with a platform. Similarly, the utility a consumer $s$ enjoys by patronizing platform 2 is the same as

\footnotetext{
${ }^{14}$ See OECD (2018a) pg. 6. Also See OECD (2018b). They both discuss the generally negative impact of advertising has on consumers. Also, see Online platforms and digital advertising Market study: interim report, 2019 (2019) which suggests that an increase in advertising on a platform implies degraded quality on the platform, pg. 57, pg. 87 .
} 
before

$$
u_{2}=v+g_{2} \cdot \theta \mathbf{E} D_{2}-\gamma A_{2}+s / 2 .
$$

where $g_{2}$ is the indicator function that takes a unit value if platform 2 is an ad-funded platform else it takes value of 0 . We denote by $A_{2}$ the number of advertisers active on the platform 2 and the consumer belief on the total mass of consumers affiliating with a platform as $\mathbf{E} D_{2}$. Consumers prefer to join platform 1 over platform 2 whenever $u_{1}>u_{2}$ or

$$
s<s^{*}:=\theta\left(g_{1} \cdot \mathbf{E} D_{1}-g_{2} \cdot \mathbf{E} D_{2}\right)-\gamma\left(A_{1}-A_{2}\right)
$$

The demand for platform 1 is represented by all consumers with $s<s^{*}$ and the remaining consumers will join platform 2. Hence,

$$
D_{1}=F\left(s^{*}\right) \quad D_{2}=1-F\left(s^{*}\right) .
$$

The demand denoted by $F(s)$ has the following properties.

Assumption 1. $F(\cdot)$ is smooth, with strictly positive density function $f(\cdot) . F(\cdot)$ is symmetric around zero and is such that the monotone hazard rate $\frac{f(s)}{1-F(s)}$ is increasing with $s$.

Advertisers. On the other (advertiser's) side of the market, advertisers launch ad campaigns on a platform given the price set by platforms. We model advertisers as firms that benefit from interactions with consumers. The value of such interactions is denoted by $\phi$ for the advertisers. These represent a measure of the cross network benefits in this side of the market. These advertising firms are charged a price $p_{i}$ for affiliating with a platform and accessing the mass of consumers on that platform.

Advertisers are distributed according to their type $(k \in[0, \infty))$ with a $\operatorname{cdf} \Lambda(\cdot)$ and density $\lambda(\cdot)$. These advertiser types can be understood as the entry costs or as an outside option that these advertisers face when joining each platform.

The utility of advertiser of type $k$ when joining platform $i$ is $v_{i}=\phi D_{i}-p_{i}-k$, and they do so for any $v_{i}>0$, that is for any $k<k_{i}:=\phi D_{i}-p_{i}$. Everything else constant, the mass of advertisers on a platform rises when $\phi$ rises and falls in the price charged by the platform for access to consumers. For simplicity, we ignore increasing returns to scale (or entry cost synergies) for the fringe firms. These synergies only increase the incidence of multihoming fringe firms while our main results are unchanged.

As a result, the mass of advertisers on platform $i$ is

$$
A_{i}=\Lambda\left(k_{i}\right) .
$$

Assumption 2. $\Lambda(\cdot)$ is smooth, with strictly positive density function $\lambda(\cdot)$ and $\lambda^{\prime}(\cdot)>0$.

The economic intuition behind $\lambda^{\prime}>0$ is that there are larger number of advertisers with relative higher cost of advertising than low-cost ones. Also, this is a sufficient condition for the monotone hazard rate to be increasing in $k$.

Platforms. The CMA describes the platforms we study in this paper in their recent report. ${ }^{15}$ These platforms compete to attract consumers by offering their core services for free. Once

\footnotetext{
${ }^{15}$ See Online platforms and digital advertising Market study: interim report, 2019 (2019).
} 
they acquire a critical mass of consumers, they make money from business users on another side of the platform. ${ }^{16}$ As in the report, platforms are advertising funded and do not charge consumers for access to the platform services. Instead, the platforms act as a bottleneck for advertisers for access to consumers. They charge advertisers a fee for accessing consumers on the platform. We study two types of such platforms. Firstly, platforms that content/service oriented which are denoted by the indicator function $g_{i}=0$. Secondly, platforms that also offer consumers a network benefit from interacting with each other $g_{i}=1$. These platforms exhibit same-side network effects denoted by $\theta \cdot{ }^{17}$

The platforms decide on the advertising price to maximize their profit which is given by the expression below

$$
\Pi_{i}\left(g_{i}, g_{j}\right)=p_{i} \cdot A_{i} .
$$

We further assume the following to ensure an interior pricing solution.

Assumption 3. We assume that $1>f(s)\left(\theta\left(g_{1}+g_{2}\right)-\gamma \phi \lambda(k)\right)$

Timing. The timing of the game is as follows. In the first stage, platforms set prices to advertisers simultaneously. In the second stage, advertisers and consumers decide simultaneously which platform to join.

\section{Analysis}

The indicator functions $\left(g_{1}, g_{2}\right)$ make the model very flexible and allow us to study a large variety of competitive settings such a competition between: two standard platforms, two social media platforms, a social media platform and a standard platform and platforms with consumer congestion externality. Before we proceed to a type of competitive setting, we discuss the characteristics shared by these advertising funded platforms.

Regardless of the type of platform competition, a platform $i$ sets price levels to maximize profits. The first order conditions for a platform setting prices are given as follows:

$$
\frac{\partial \Pi_{i}\left(g_{i}, g_{j}\right)}{\partial p_{i}}=A_{i}\left(g_{i}, g_{j}\right)+p_{i} \frac{\partial A_{i}\left(g_{i}, g_{j}\right)}{\partial p_{i}}=0
$$

with $\frac{\partial A_{i}\left(g_{i}, g_{j}\right)}{\partial p_{i}}<0$ which is ensured by Assumption 3 .

We discuss the impact of a unilateral price increase by a platform $i$ on consumer and advertising demand in the market in the following Lemma:

Lemma 1. A unilateral increase in advertising price by platform $i$ affects market demands in the following way:

$$
\begin{array}{ll}
\frac{\partial A_{i}\left(g_{i}, g_{j}\right)}{\partial p_{i}}<0, & \frac{\partial A_{j}\left(g_{j}, g_{i}\right)}{\partial p_{i}}<0 \\
\frac{\partial D_{i}\left(g_{i}, g_{j}\right)}{\partial p_{i}}>0, & \frac{\partial D_{j}\left(g_{j}, g_{i}\right)}{\partial p_{i}}<0
\end{array}
$$

\footnotetext{
${ }^{16}$ Examples of such platforms are abundant such as Youtube, Facebook, search engines and many others. See CMA interim report

${ }^{17}$ The model allows us to look at the two cases, when consumers obtain a positive value from other consumers and the case when consumers obtain a disutility from the presence of others which we call consumer congestion.
} 
The above result shows that a unilateral increase in price at a platform leads to an increase in consumer demand, a decrease in advertising demand as well as a decrease in advertising demand at the rival platform. The intuition for the above result is as follows. The direct impact of an increase in advertising price by platform $i$ is lowered advertising intensity on that platform. This results in an increase in consumer demand for that platform. This increase in consumer demand at platform $i$ results in a decrease in consumer demand at platform $j$ which reduces the amount of advertisements of platform $j$. The decrease in advertising demand at the rival platform $(j)$ due to a price increase on platform $i$ is a unique link that we illustrate in this paper. This link is further compounded by the presence and intensity of same-side network effects. This is because under these network effects $(\theta)$ an additional consumers increases the attractiveness of a platform to advertisers in two ways. Firstly, a consumer by joining a platform increases the attractiveness of that platform (to advertisers). Secondly, once it joins a platform due to the positive same-side network effect it further attracts more consumers to that platform which further increases the attractiveness of that platform. Therefore, the value of a consumer to a platform is the sum of the value generated by that consumers on that platform and all the other consumers it potentially attracts. This is expected to result in fiercer competition between platforms to attract consumers. In the next subsections, we discuss the different market configurations and the ensuing competition.

In following subsections, we first look at the pricing strategy for the case when two standard advertising funded platforms $\left(g_{1}=g_{2}=0\right)$ compete. Then, we look at the case when two advertisement funded social media platforms $\left(g_{1}=g_{2}=1\right)$ compete. Finally, we also look at the asymmetric case when a social media platform competes with a standard advertising funded platform $\left(g_{1}=1, g_{2}=0\right){ }^{18}$

\subsection{Competition between standard advertising funded platforms}

In this subsection, we have in mind competition between platforms that earn through advertisements and do not have same-side network effects. Examples of such platforms include Youtube, Vimeo and Dailymotion. This is the case when $g_{1}=g_{2}=0$. We abstract away from competition in platform services and assume, for all practical purposes the platforms have very similar content. Instead, we focus on advertisement pricing when advertising is viewed as a nuisance by consumers. The platforms compete for consumers by choosing the mass of active advertisers on a platform by setting advertising prices appropriately.

The first order conditions are described in 5. We discuss a symmetric equilibrium in the following Lemma.

Lemma 2. The equilibrium price is symmetric and given as

$$
p_{1}^{*}=p_{2}^{*}=p^{*}=\Lambda\left(k^{*}\right) \frac{1+2 f(0) \gamma \phi \lambda\left(k^{*}\right)}{\left.\lambda\left(k^{*}\right)\left[1+f(0) \gamma \phi \lambda\left(k^{*}\right)\right)\right]}
$$

where $k^{*}=\phi / 2-p^{*}$. The corresponding consumer demand and advertisement demand on a platform are $D_{1}^{*}=D_{2}^{*}=F(0)=1 / 2$ and $A_{1}^{*}=A_{2}^{*}=\Lambda\left(k^{*}\right)$ respectively.

\footnotetext{
${ }^{18}$ This case provides insights on a setting where there is a dominant platform that exerts market power vis a vis the rival.
} 
Proof. See Appendix 9.2.

We focus on a symmetric equilibrium and discuss the various network effects impact prices in the presence of competition. The following lemma describes the comparative static of prices in the network effects.

Proposition 1. The equilibrium advertising price on a platform is rising in the consumer nuisance from advertisers $(\gamma)$.

Proof. See appendix 9.3

The above result is very intuitive. An increase in $\gamma$ implies consumers have a higher disutility from the presence of advertisers on a platform. This creates a pressure on the platform to increase its advertising price to attract consumers on the platform. An increase in price leads to a fall in the mass of advertisers active on a platform resulting in a fall in advertiser surplus.

\subsection{Competition between social media platforms}

In this subsection, we look at the case where two social media platforms compete. This is the case when $\left(g_{1}=g_{2}=1\right)$. The main difference between a social media platform (SMP) and a standard advertising funded platform is that consumers on a SMP also value the presence of other consumers on that platform. This is what we call same-side network effects denoted by $\theta>0$. In this subsection, we try to understand how consumers' value from the interaction with other consumers $(\theta>0)$ on that platform impacts prices and competition. In this setting, both same-side and cross-side network effects jointly impact prices. These two types of network effects impact consumer utility in opposite direction and hence one might conjecture that they impact consumer prices also in opposing directions. This subsection helps understand how this tension between the two opposing effects impacts competition and advertising prices.

Lemma 3. In the case when $\left(g_{1}=g_{2}=1\right)$, the equilibrium prices are symmetric and given as

$$
p_{1}^{*}=p_{2}^{*}=p^{*}=\Lambda\left(k^{*}\right) \frac{1-2 f(0)\left[\theta-\gamma \phi \lambda\left(k^{*}\right)\right]}{\lambda\left(k^{*}\right)\left[1-f(0)\left(2 \theta-\gamma \phi \lambda\left(k^{*}\right)\right)\right]}
$$

and

$$
D_{1}^{*}=D_{2}^{*}=F(0)=1 / 2
$$

and

$$
A_{1}^{*}=A_{2}^{*}=\Lambda\left(\phi / 2-p^{*}\right)
$$

Proof. See Appendix 9.4.

One can notice that same-side network effects $(\theta)$ play an important role in the pricing strategy of a SMP. To further understand how same-side network effects interact with the cross-side network effects in the model, we do some comparative statics of prices with respect to $\theta$ and $\gamma$.

Proposition 2. The equilibrium advertising prices on a platform

- are rising in $\theta$ unambiguously. 
- are rising in $\gamma$ if $1>2 \theta f\left(s^{*}\right)$. Else, prices are falling in $\gamma$.

Proof. See appendix 9.5

We find that a rise in consumer valuation due to the presence of other consumers increases competition for consumers between platforms and leads to a reduction in the number of active advertisers. The intuition for this is the following. An increase in $\theta$ makes every consumer that affiliates with a platform more valuable. Every consumer that joins a platform has a higher attraction effect on other consumers. This leads to platforms aggressively competing for consumers. This competition for consumers is through increasing advertising prices to reduce the mass of active advertisers which in turn might attract consumers. This result shows that an increase in the same-side network effect increases competition and actually reduces consumer nuisance generating advertising.

A rise in $\gamma$ implies increased consumer sensitivity to advertisement intuitively should result in a fall in advertisement through increased prices. However, we find that it is not so straightforward as in the case without same side network externalities (i.e. $\theta=0$ ). Specifically, we find that for sufficiently small levels of same-side network externalities, for $\theta<\frac{1}{2 f\left(s^{*}\right)}$, advertising price rises and the total mass of advertisers falls. This result is similar to the case without same-side network externalities. Interestingly, we find that the opposite occurs if $\theta$ is large enough. Specifically, for $\theta>\frac{1}{2 f\left(s^{*}\right)}$, we find an increase in $\gamma$ leads to increase in advertisement. These results hold in a simple Hotelling set-up. We find that for $t>\theta$, prices are falling in $\gamma$ and vice versa.

Consumer surplus and Media see-saws An increase in same-side network effect increases consumer surplus. The increase in consumer surplus is two fold. Firstly, a direct effect of an increase in the same-side network effects increases the utility of consumers from the presence of rivals. Secondly, there is an indirect channel that increases consumer surplus through an increase in advertising price resulting in lower advertising intensity. This leads to a fall in advertising side surplus. The media See-Saw exists when $\theta$ rises.

The effect of an increase in consumer aversion to advertisements $(\gamma)$ leads to ambiguous results on consumer surplus as in the case of $g_{1}=g_{2}=0$. As before, for $1>2 \theta f\left(s^{*}\right)$, there is a tension between the negative direct effect and the positive indirect effect of an increase in $\gamma$. In contrast, for the case when $1>2 \theta f\left(s^{*}\right)$, the fall in consumer surplus is unambiguous as the indirect effect is also negative. In case when $1>2 \theta f\left(s^{*}\right)$, firm surplus is falling (due to advertising prices rising in $\gamma$ ) as well as consumer surplus. In this case, the Media See-Saw does not exist. On the other hand when $1<2 \theta f\left(s^{*}\right)$, producer surplus rises while consumer surplus falls with a rise is $\gamma$. In this case, we find that the Media See-Saw exists.

\subsection{Competition between a social media platform and a standard advertising funded platform}

In this subsection, we try to understand the competition between two different types of advertising funded platforms such as a standard platform and a social media platform. We assume that platform 1 is a social media platform $\left(g_{1}=1\right)$ and platform 2 is a standard advertising funded platform $\left(g_{2}=0\right)$. The competition between social media platform, $\theta>0$, and a standard content driven platform is asymmetric. All else equal, the market is tilted towards 
favoring the social media platform. This case allows us to study how market power of platforms impacts platform competition and consumers.

The first order conditions for the two platforms are given as follows:

$$
\begin{aligned}
& \frac{\partial \Pi_{1}(1,0)}{\partial p_{1}}=A_{1}(1,0)+p_{1} \frac{\lambda\left(k_{1}\right)\left[f\left(\hat{s}^{*}\right)\left(\theta-\gamma \phi \lambda\left(k_{2}\right)\right)-1\right]}{1-f\left(s^{*}\right)\left(\theta-\gamma \phi\left(\lambda\left(k_{1}\right)+\lambda\left(k_{2}\right)\right)\right)}=0 \\
& \frac{\partial \Pi_{2}(0,1)}{\partial p_{2}}=A_{2}(0,1)+p_{2} \frac{\lambda\left(k_{2}\right)\left[f\left(\hat{s}^{*}\right)\left(\theta-\gamma \phi \lambda\left(k_{1}\right)\right)-1\right]}{1-f\left(s^{*}\right)\left(\theta-\gamma \phi\left(\lambda\left(k_{1}\right)+\lambda\left(k_{2}\right)\right)\right)}=0
\end{aligned}
$$

For ease of explanation, for this case we exploit a simple set up with uniform distribution for consumers and advertisers.

Lemma 4 . The prices are asymmetric and given as $\hat{p}_{1}^{*}(1,0)>\hat{p}_{2}^{*}(0,1)$ and $D_{1}^{*}(1,0)>D_{2}^{*}(0,1)$ and $A_{1}^{*}(1,0)>A_{2}^{*}(0,1)$

Proof. See Appendix 9.10.1.

Interestingly, a higher advertising price at the social media platform vis a vis the standard platform does leads to a higher mass of active advertisers on the social-media platform. This higher advertising price is mainly due to its ability to attract a greater mass of consumers (due to $\theta$ ) and hence also a greater mass of advertisers. It is the asymmetric form of competition that creates a "quality" differential between the two platforms and the affords the social media platform ability to charge a higher price whilst attracting a larger mass of consumers and advertisers.

In a symmetric competition set-up, a higher advertising price is an indication of fiercer competition for consumers and lower mass of advertising. It is straightforward to notice that the advertising price in a symmetric social media competition set-up is higher than the symmetric standard advertising platform set-up. The presence of same-side network effects increases competition for consumers and hence higher prices to advertisers. Interestingly, we find that the advertising price of the social media platform in the asymmetric set-up is higher than the price in the symmetric set-up. In this case, the reason for the higher price is its market power due to its better ability to attract consumers. As discussed in the previous paragraph, this increased price does not imply lower advertising demand but rather higher advertising demand than the symmetric case where competition is between two standard platforms i.e. $A_{1}(1,0)>A_{1}(0,0)>A_{1}(1,1)$. This result is similar to the classical case of competition between vertically differentiated firms where the higher quality firm sets higher prices as well as attracts a larger mass of consumers.

\subsubsection{Market power and Consumer exploitation}

The presence of $\theta>0$ implies that the social media platform has an advantage in attracting consumers vis a vis its rivals. This same-side effect parameter can be used as a proxy for market power impacts the players in the market and affects competition. This exercise albeit simple provides insightful results. The following proposition summarizes the insights.

Proposition 3. An increase in market power $\theta>0$ of platform 1 leads to

- $\frac{\partial p_{1}}{\partial \theta}>0, \frac{\partial A_{1}}{\partial \theta}>0$ and $\frac{\partial D_{1}}{\partial \theta}>0, \frac{\partial \Pi_{1}}{\partial \theta}>0$. 


$$
\text { - } \frac{\partial p_{2}}{\partial \theta}<0, \frac{\partial A_{2}}{\partial \theta}<0, \frac{\partial D_{1}}{\partial \theta}<0 \text { and } \frac{\partial \Pi_{2}}{\partial \theta}<0 \text {. }
$$

The above proposition shows how increased market power of a platform affects the market. In this setting, market power is the ability of a platform to attract a larger mass of consumers than the rival all else equal. We find that an increase in market power of platform 1 results in an increase in advertising price along with an increase in advertising intensity on that platform. The advertised intensity is however not large enough to reduce consumer demand at the dominant platform. Therefore, consumer demand rises on the social media platform. This result is actually aligned with what is currently observed in the market. The advertising price on dominant platforms is consistently higher than its rival. ${ }^{19}$ Moreover, the dominant platform profit increases while the rival's profit falls with an increase in $\theta$. This is because an increase in $\theta$ leads to an increase in consumer attraction of consumers which then leads to an increase in advertising on the platform albeit at a higher price. The rival platform is handicapped in its ability to attract consumers and must therefore set lower advertising prices to compensate advertisers active on the platform.

Case study: Google and Bing The search and query market is characterized by two main players, Google and Bing, that have a market share of above $4 \%$. Google is by far the dominant player in this market with consistent market shares of over $90 \%$ in most jurisdictions with Bing being a distant second with a market share of 5\%. Google's dominance and ability to attract a larger audience through better search results are self-propagating. A larger consumer base allow it to improve its search algorithm which further attracted new consumers. This advantage confers on google a significant market power which is self-reinforcing. The proxy for market power, $\theta$, also behaves similar to the dominance of Google from a larger user base. This is because in the search and query market, an increase in the number of consumers active on the platform improves search results on the platforms and further attracts new consumers. ${ }^{20}$ This results in a cycle that is hard to break by a rival. This is observed by the consistently higher advertising prices Google charges advertisers in comparison to Bing. ${ }^{21}$ Moreover, Google also has much higher advertising demand and consumer demand which confirms the results we obtain in a dominant platform setting. This anecdotal evidence provides some confirmation to the results we find in the case where one platform has market power.

\section{Merger between competing platforms}

In this subsection, we try to understand how a merger between two competing digital platform impacts advertising pricing on platforms. There has been a lot of discussion on the Facebook/Instagram merger and its implications for competition. ${ }^{22}$ Specifically, recent reports suggest that the limited ability of advertisers to negotiate and the large market power of platforms make advertisers vulnerable. It is suggested that platforms like Facebook and Google have the ability to charge more than if competition was effective. ${ }^{23}$ We provide evidence that

\footnotetext{
${ }^{19}$ See CMA interim report for the difference in cost per click for Google searech and Bing search, pg. 167.

${ }^{20}$ See Digital Platforms Inquiry: Final Report, 2019 (2019), pg. 66.

${ }^{21}$ See Online platforms and digital advertising Market study: interim report, 2019 (2019) figure 5.4, pg 167.

${ }^{22}$ For a comprehensive list of mergers in digital markets, see Gautier \& Lamesch (2020) and Argentesi, Buccirossi, Calvano, Duso, Marrazzo \& Nava (2019).

${ }^{23}$ See Digital Platforms Inquiry: Final Report, 2019 (2019) discussion on page 119. Also, see Online platforms and digital advertising Market study: interim report, 2019 (2019), pg. 150.
} 
this might not be the case. Instead, market power of platforms gained through mergers actually reduces advertising price and aligns the incentive of the platform with the advertising side. ${ }^{24}$

In this section, we suppose that platforms 1 and 2 merge and then look at how this impacts pricing strategy of firms. ${ }^{25}$ We then do comparative static for the case when two platforms are standard ad-funded platforms and social-media ad-funded platforms.

The merged entity sets prices to maximize its profit denoted by

$$
\max _{p_{1}, p_{2}} \Pi^{M}=p_{1} A_{1}+p_{2} A_{2}
$$

The platforms sets prices at platform $i$ that solve the following FOCs

$$
\frac{\partial \Pi^{M}}{\partial p_{i}}=A_{i}+p_{i} \frac{\partial A_{i}}{\partial p_{i}} p_{j} \frac{\partial A_{j}}{\partial p_{i}}=0
$$

Post merger, the (merged) platform now internalizes the externality it generates on the rival when setting prices (i.e. $p_{j} \frac{\partial A_{j}}{\partial p_{i}}$ ). The impact of such internalization on prices is discussed in the following proposition.

Proposition 4. The symmetric equilibrium advertising price of the merged entity is lower than the case when they are separated i.e., $p_{1}^{M *}=p_{2}^{M *}:=p^{M}<p^{*}$. This results in a larger total mass of active advertisers post-merger $A_{1}^{M *}=A_{2}^{M *}>A^{*}$

The above result is obtained by substituting the prices in the case of separation into the FOCs, we get

$$
\left.\frac{\partial \Pi^{M}}{\partial p_{1}}\right|_{p_{1}=p_{2}=p^{*}}=p_{2} \frac{\partial A_{2}}{\partial p_{1}}<0 .
$$

The above is negative as $\frac{\partial A_{2}}{\partial p_{1}}<0$. This results in post-merger prices for advertisers being set lower than the case when the two platforms were separate entities. This is because a merged platform internalizes the negative impact of an increase in its price on the rival platforms advertisement demand. In particular, an increase in price of advertisements by a platform results in decrease in active advertisers on that platform which attracts consumers towards that platform. In turn, this leads to a fall in advertising demand on the rival platform. Post merger, the negative impact of an increase in price on the rival is internalized resulting in lower prices post-merger than the case when the two-platforms were separated. These results are valid regardless of the case if the two merging platforms were standard platforms $\left(g_{1}=g_{2}=0\right)$ or social media platforms $\left(g_{1}=g_{2}=1\right)$. Next, we try to understand how these prices are affected by the network effects. We summarise the comparative static of prices in the following proposition.

\footnotetext{
${ }^{24}$ We do not specifically suggest that advertisers obtain more surplus. This is because the advertising side is fraught with a lack of transparency and includes multi-stages between the advertisers and the platform. Any accrual of benefits on the advertising side to advertisers will be subject to competition on the advertising supply chain. Therefore, any lack of accrual of advertising benefits to actual might not be due to the lack of competition between platforms but a lack of competition in the supply chain. In the paper, we abstract away from modeling competition in the supply chain and only look at surplus in the advertising side. For a detailed description of the ad-tech supply chain, see Digital Platforms Inquiry: Final Report, 2019 (2019), pg. 152.

${ }^{25}$ For expositional purposes, we look at symmetric competition case. A detailed analysis of the asymmetric competition setting $\left(g_{1} \neq g_{2}\right)$ can be produced upon request.
} 
Proposition 5. For $g_{1}=g_{2}=g \in\{0,1\}$, the post-merger prices are not affected by a change in same-side network effects $\left(\frac{\partial p^{M, *}}{\partial \theta}=0\right)$ and consumer nuisance from advertisement $\left(\frac{\partial p^{M, *}}{\partial \gamma}=0\right)$.

Proof. See appendix 9.6.

We describe below how the above results contrast with the pre-merger competitive case when competition is between two standard advertising funded platforms and social media platforms.

The above results show that an increase in $\gamma$ does not impact the post-merger price. When platforms compete an increase in consumer sensitivity to advertisement leads to an increase in advertising price. If the price at a platform is not increased, the rival platform would increase the price attract consumers due to lower advertising activity on the platform. This leads to an upward pressure on advertising prices. However, post-merger this is not the case. This is because post-merger platform internalizes the negative effect of an increase in advertising price on the rival platform's profit. This neutralizes the upward pricing pressure and as a result platform prices do not change with a change in the consumer disutility from the presence of advertisers on a platform.

The proposition below discusses how platform profits are impacted with a change in advertising side network benefit.

Proposition 6. Platform profits rise with advertising side network benefits. In particular, $\frac{\partial \Pi^{M}}{\partial \phi}>0$.

The proof for the above can be seen in direct effect of an increase in $\phi$ on platform profits. The direct effect of an increase in $\phi$ is given as

$$
\frac{\partial \Pi^{M}}{\partial \phi}=\underbrace{\frac{\partial p_{i}^{m}}{\partial \phi}}_{+} A_{i}^{M}+p_{i}^{M} \underbrace{\frac{\partial A_{i}^{M}}{\partial \phi}}_{+}+p_{j}^{M} \underbrace{\frac{\partial A_{j}^{M}}{\partial \phi}}_{+}>0
$$

An increase in $\phi$ results in an increase in advertising price and advertising demand on both the differentiated entities of the merged platform. This is because an increase in $\phi$ implies increased per consumer value to advertisers after taking into account the effect of an increased price. This allows platforms to extract a portion of that gain. An increase in $\phi$ leads to an increase in platform profits as well as an increase in advertising side surplus. This implies profit of the platform and the advertising side are aligned post-merger. This is in contrast to the discussion in the recent reports regarding market power of platforms vis a vis advertisers. A merger actually aligns the incentives of the these two players. Any lack of accrual of benefits to the advertisers could just be the competition intensity along the ad-tech supply chain. ${ }^{26}$ In the following subsection, we discuss the impact on consumers, potential theories of harm and the associated remedies.

\subsection{Discussion on consumer surplus and privacy concerns}

A merger between competing zero-pricing platforms provides new insights into the impact of a merger on consumers and advertisers. In particular, we find that post-merger advertising prices are not impacted by consumer side externalities, neither both positive same-side effects (consumer benefit from the presence of other consumers, $\theta$ ) nor cross-side consumer disutility

\footnotetext{
${ }^{26}$ See Biglaiser et al. (2019) for a detailed description of the supply chain, pg. 152 .
} 
(consumer nuisance from advertisements, $\gamma$ ). The advertising price is only impacted by the firm side positive network effect, $\phi$. Furthermore, the advertising price is lower post-merger than the competitive setting resulting in a higher mass of active advertising firms. This is because firms do not compete to attract consumers resulting in an increase in advertisements beyond competitive levels while disregarding consumer disutility. The merged platform sets advertising prices to maximize its profits which also increase advertiser profits as the total mass of advertisers increases. The following proposition discusses the impact of the merger on the consumers' and advertisers' side.

Proposition 7. The merger of two platforms leads to a fall in consumer surplus and a rise in advertiser surplus.

The following discussion will endeavor to quantify the effects of a merger on consumers and advertisers. The change in consumer surplus when consumer join platform 1 between the pre-merger and post-merger scenario is given as

$$
\begin{aligned}
& C S_{1}^{*}-C S_{1}^{M *}=\int_{\underline{s}}^{0}\left[\theta g_{1}\left(D_{1}^{*}-D_{1}^{M *}\right)-\gamma\left(A_{1}^{*}-A_{1}^{M *}\right)\right] f(s) d s \\
& C S_{1}^{*}-C S_{1}^{M *}=\gamma\left(A_{1}^{M *}-A_{1}^{*}\right) / 2>0
\end{aligned}
$$

The second expression is obtained taking into account the fact that under a symmetric equilibrium $D_{1}^{*}=D_{1}^{M *}=1 / 2$ and the total mass of advertisers active on platform 1 post-merger is larger than pre-merger, $A_{1}^{M *}>A_{1}^{*}$. The above result provides us with the harm associated with a merger to consumers. Since platforms do not charge a price, the harm arises due to increased advertisement levels on a platform post-merger. The same exercise can be repeated for platform 2. Therefore, one finds that consumer surplus falls post-merger. Next, we look at the impact on advertisers' side.

The advertising side surplus is given as follows:

$P S_{1}^{*}-P S_{1}^{M *}=\int_{0}^{k_{1}^{*}}[\phi \underbrace{\left(D_{1}^{*}-D_{1}^{M *}\right)}_{=0}-\underbrace{\left(p_{1}^{*}-p_{1}^{M *}\right)}_{+}] \lambda(k) d k-\int_{k_{1}^{*}}^{k_{1}^{M *}}\left[\phi D_{1}^{M *}-p_{1}^{M *}-k\right] \lambda(k) d k<0$

The above expression clearly demonstrates the increase in advertising side surplus post-merger as $D_{1}^{*}=D_{1}^{M *}=1 / 2$ and $p_{1}^{*}>p_{1}^{M *}$. The increase in advertising side surplus is two-fold. The advertisers types already active on platform 1 pre-merger $\left(k<k^{*}\right)$ obtain a reduction in prices while consumer demand at the platform does not change. Secondly, there is an expansion of advertising demand at the platform 1 post-merger due to reduced prices. Therefore, one finds that advertising surplus rises post-merger. The above proposition confirms the Media See-Saw result that Anderson \& Peitz (2020) finds as a result of a merger. We find that platform profits are aligned with the advertising side profits while consumers are hurt as a result of the merger.

\section{Merger Theories of Harm and potential remedies}

In such markets, consumer price is not a variable of competition as it is set at zero. This creates a regulatory grey area as traditionally competition authorities have focused on a merger's impact on prices (recently on innovation incentives) and thereby able to quantify the damage 
to consumers. For instance, most of the tools are focused towards a consumer price such as the tool for market definition (SSNIP) ${ }^{27}$, the upward pricing pressure test (UPP) among others. This leads to a regulatory quagmire for the anti-trust authorities which must often balance public, political and commercial interests.

Under such circumstances, the quantification and identification of potential harm and suggestion of effective remedies is paramount. As suggested in the Scott Morton et al. (2019), a mistake in the approval process in such markets could have long-lasting effects. ${ }^{28}$ We agree with Waehrer (2016) regarding the use of platform quality as a measure of competitive intensity on the consumer side. We are also well aware of the ambiguity in defining good or bad quality of a platform's services. As the OECD (2018a) rightly points out quality is subjective, multidimensional and often hard to quantify in comparison prices. However, some of the measures of quality in the online market can be measured just as easily as advertising prices. For instance, advertising intensity to consumers. Advertising intensity per customer for a unit of time spent on a platform is relatively easy to quantify.

An important takeaway from our analysis is that a merger between two competing platforms makes the advertising prices intransigent in consumer side network effects. This result presents a very bleak outcome for consumers. Platform profits are rising in the value generated by consumers on the advertising side. This implies platforms have the incentive to implement strategies that increase advertising side value from each consumer affiliated to the platform. As a consequence of this, consumers are specially vulnerable to exploitative behavior by the merged platform in order to increase its profits. The merged entity would be unchecked in its ability to increase its profits to the detriment of consumer welfare. A platform could employ multiple strategies towards this. Such strategies include more frequent and longer advertisements, improved consumer targeting, better analytics tools as well as a significant increase in consumer data collection. The latter could result in onerous and invasive privacy terms dictated to consumers to the benefit of advertisers. We discuss possible consumer harm arising from a merger and the potential behavioral remedies to correct for them.

\section{Theory of Harm: Post-merger advertising intensity increases}

The merged entity is not constrained by a rival platform in setting its advertising prices. It internalizes the "negative advertising externality" on the rival and on equilibrium sets lower advertising prices to attract a larger mass of advertisements on the platform. This results in consumer harm due to increased advertisements on a platform as a direct consequence of the merger. The simplified expression for the difference in consumer surplus in equation 8 highlights this. The fall in consumer surplus post-merger is directly linked to the difference in the mass of advertisements pre- and post-merger. Consumer surplus clearly falls post-merger due to increased advertisement levels on the merged platforms.

\section{Merger remedy: Advertising caps as a merger remedy}

A possible merger remedy employed by Anti-trust authorities in a setting where prices do not play a rule might include "Advertising caps". This is also a remedy suggested by Anderson \&

\footnotetext{
${ }^{27}$ The SSNIP test often plays a central role in the market definition exercise at the European Commission, See https://ec.europa.eu/competition/international/multilateral/2012 ${ }_{j} u_{m}$ arket $_{d}$ efinition $n$ n.pdf

${ }^{28}$ See Scott Morton et al. (2019) pg. 16.
} 
Peitz (2020) that imposes on the merged entity to a binding advertisement cap level. Platforms are thus unable to subject consumers to an advertisement intensity (for instance, number of advertisements per consumer per unit spent on the platform) above a certain pre-determined and agreed upon level. It will always be up to debate what the level of advertisement intensity should be. It is obvious that due to Media see-saws in this setting any advertising cap that is binding will hurt platforms. This result mirrors Anderson \& Peitz (2020) where an advertisement cap if binding, benefits consumers, hurts advertising firms and platforms. However, one must take into account that the two platforms do not compete for consumers (post-merger) and their incentives are aligned in favor of the advertisers while consumers interests are ignored. We suggest a regulatory policy of limiting advertisements as on TV networks should be implemented for such platforms. ${ }^{29}$ In particular, we suggest that the firms must commit to keeping the advertising intensity at the pre-merger levels. This does not degrade consumer experience on a platform while advertising side's surplus is also unchanged (as advertising price would be set at pre-merger levels). Through such a strategy, in comparison to pre-merger, both consumer side's and advertising side's welfare is unchanged post-merger.

\section{Theory of Harm: Post-merger consumer data extraction increases}

A digital platform's ease and ability to extract such data is a hotly debated topic in almost every policy circle and jurisdiction concerned with the ability and the possible abuse of consumer data to the detriment of consumers. In our setting, a merged platform if unchecked by competition will have the incentive to extract large amounts of consumer data if such data increased advertisers' willingness to pay and hence increased its profits. Moreover, since consumers find such platforms indispensable for their daily use $^{30}$, these platforms will be easily able to set exploitative and intrusive data extraction terms and conditions for use of the services. ${ }^{31}$ Moreover, since consumers do not have any viable alternatives they will no option but to accept the terms. ${ }^{32}$ Thereby resulting in loss of control over their own data.

\section{Merger remedy: Limits on data extraction as a merger remedy}

From the analysis, it is straightforward that post-merger platforms do not consider consumer side network effects when making pricing decisions. Instead, only the advertising side network effect, $\phi$, is considered. Also, the Media See-Saw is such that platform and advertising firm side profits are aligned. Therefore, firms might employ strategies to increase advertising side per-consumer gain $\phi$. Such strategies can include a larger amount of consumer data extraction that allows better targeting of consumers. This might result in an increase $\phi$. The impact of such a strategy to increase $\phi$ does not consider the impact on the consumer side. Such increased data extraction activity might also increase $\gamma$ and therefore reduce consumer disutility from advertisements. ${ }^{33}$ Thus, creating a harm for consumer post-merger due to disregard of consumer

\footnotetext{
${ }^{29}$ See for example, EU directive 97.

${ }^{30}$ See Brynjolfsson et al. (2019) for a discussion on how valuable these services are for consumers.

${ }^{31}$ See Reyna (2018) that suggests a lack of competition between platforms will allow platforms to reduce privacy without losing consumers or revenue.

${ }^{32}$ See Scott Morton et al. (2019) for a discussion on barriers to entry and expansion due to network effects.

${ }^{33}$ Consumers value for privacy is a well established fact, see Britainthinks (2018). Also, the entry of online search platform that protect consumer privacy such as Duck Duck go are evidence that consumers value such services.
} 
interests due to the merger in favor of increasing platform profits. We suggest that regulators must take pro-active action to ensure privacy of consumers is ensured through maintenance of data extraction limits at the competitive levels post-merger. Any post-merger increase in data extraction must be well justified by the gains they provide consumers.

\section{Extensions}

\subsection{Multi-homing consumers}

Multi-homing of consumers is an important feature of online markets. It has also been discussed extensively in the literature such as Athey et al. (2016), Belleflamme \& Peitz (2019a), Bakos \& Halaburda (2019) and others. ${ }^{34}$. We discuss this setting not only due to theoretical curiosity but also because of its ability to provide insights as to how a monopolist with demand expansion might price on the advertising side.

In the benchmark model, we assumed consumers single-home and platforms compete for such consumers. In this subsection, we describe a setting where consumers multi-home where sameside and cross-side network effects interact. Multi-homing of consumers implies that platforms do not compete with each other for consumers. With the absence of the competitive constraint, platforms are freely able to set advertising prices to maximize profits. As a result, this setting can also sheds light on how platform pricing interacts with network effects when the market consists of only one zero pricing platform which has negligible competitive constraints.

The utility of a multi-homing consumers denoted by $u^{m h}$ is as follows:

$$
u^{m h}=2 v-\gamma\left(A_{1}+A_{2}\right)+\theta\left(g_{1} \cdot \mathbf{E} D_{1}+g_{2} \cdot \mathbf{E} D_{2}\right) .
$$

For simplicity, I assume that consumer utility from multi-homing on the platforms is additive. This impacts the result only quantitatively while preserving its qualities nature. ${ }^{35}$

In the model, consumers decide whether to multi-home or singlehome given their type $s$. It is important to mention here that the mass of multi-homing consumers is the overlapping consumer demand on both platforms. To obtain the mass of consumers active, we compare $u_{1}$ to $u^{m h}$ and $u_{2}$ to $u^{m h}$. We place a restriction on the parameters of the model such that the additional value of joining the second platform is sufficiently low. Essentially, we want to focus on the interesting case where both single-homing and multi-homing consumers exist. ${ }^{36}$ Therefore, under sufficiently low additional value of joining a platform, an agent with a strong relative preference to platform $i$ finds single-homing on platform $i$ more valuable than multihoming, i.e. $u_{1}>u^{m h}$. Therefore, we get the consumer that is indifferent between multi-homing and single-homing on platform 1 as

$$
s<s_{1}^{*}\left(g_{1}, g_{2}\right):=2\left(\gamma \cdot A_{2}-g_{2} \theta \cdot \mathbf{E} D_{2}-v\right)
$$

\footnotetext{
${ }^{34}$ Other recent works include Ambrus et al. (2016), Calvano \& Polo (2019), D'Annunzio \& Russo (2019), Anderson et al. (2018), Choi (2010), Choi et al. (2017), Carroni et al. (2019)

${ }^{35}$ Any discount on consumer interaction with overlapping consumers will not change the results.

${ }^{36}$ The case where all consumers multi-home is not very interesting as consumer demand and advertising prices is a corner solution while we focus on an interior solution.
} 
and, similarly, $u_{2}>u^{M}$ when

$$
s>s_{2}^{*}\left(g_{2}, g_{1}\right):=2\left(v-\gamma A_{1}+g_{1} \theta \mathbf{E} D_{1}\right) .
$$

The above results in single-homing demand on platform 1 as $D_{1}^{s h}=F\left(s_{1}^{*}\right)$ and on platform 2 as $D_{2}^{s h}=1-F\left(s_{2}^{*}\right)$. The multi-homing or overlapping consumer demand is denoted as $D^{m h}=F\left(s_{2}^{*}\right)-F\left(s_{1}^{*}\right)$. Therefore, total demand on a platform is $D_{i}=D_{i}^{s h}+D^{m h}$ for $i \in 1,2$.

It is straightforward to see that consumer demand on a platform does not interact with consumer demand on the other platform. For instance, the demand on platform 1 is

$$
D_{1}=F\left(2\left(v-\gamma A_{1}+\theta g_{1} \mathbf{E} D_{1}\right)\right)
$$

The total consumer demand on a platform is a function of the consumer and advertising demands only on that platform. Therefore, the platforms behave as monopolists without any externality generated by the presence of the "rival".

We make the following assumption to ensure an interior solution for prices.

Assumption 4. We assume $1>2 f(s) \theta$.

Proposition 8. The change in prices with respect to network externalities is a follows:

- An increase in same side network effect $\theta$ leads to an increase advertising prices $\frac{\partial p^{*}}{\partial \theta}>0$ and $\frac{\partial A}{\partial \theta}>0$.

- An increase in disutility from the presence of advertisers $\gamma$ leads to an increase advertising prices $\frac{\partial p^{*}}{\partial \gamma}>0$ and $\frac{\partial A}{\partial \theta}<0$.

Proof. See Appendix 9.8.

As discussed before this setting mirrors a monopolist platform setting. This is because the consumer and advertising demands only depend on own prices. We find that advertising prices rise as same side network effects $(\theta)$ rise as well as in the case when the negative cross-side network effects $(\gamma)$ rise. It is interesting to note that the change in prices with respect to network effects is in the same direction as in the competitive setting. This qualitative equivalence of the results is, however, due to reasons different from those in the competitive setting.

In competitive setting, advertising price increases because competition creates an upwards pressure on prices so as to reduce advertising intensity on platform. In the monopolist platform (multi-homing consumers) setting, an increase in advertising price due to an increase in sameside network effects is due to increased consumer demand on that platform. The monopolist then sets prices to extract a portion of the increased advertising side profits by increasing prices. This is the classical result in an elastic demand setting where monopoly price rises due to an increase in quality of a good. An increase in consumer disutility from advertisements increases advertising prices to reduce the advertisements on a platform so as to balance the tension of consumer attraction and rent extraction.

\subsection{Platforms with consumer congestion $\left(g_{1}=g_{2}=-1\right)$}

The model we employ is very general and allows us to understand competition in a broader set of market configurations than discussed before. One such configuration is when consumers 
create negative externality $\left(g_{i}=g_{j}=-1\right)$ on each other. ${ }^{37}$ We call this consumer congestion externality and try to understand how this impacts competition in two settings when advertisements are viewed as nuisance $(\gamma>0)$ and when advertisements/content is viewed positively (in our case $\gamma<0$ ). A crude example of the latter platform could be holiday room rental platforms such as Airbnb where consumers do not enjoy congestions but value the presence of the other side.

\subsubsection{Consumer congestion with negative cross-network benefits}

In this case, consumers are hit negatively by cross-network effects from advertisers and from the congestion other consumers create on a platform. In the following proposition, we provide some insights on how prices react to a change in network effects.

Proposition 9. In a market with consumer congestion $\left(g_{1}=g_{2}=-1\right)$ and advertisements being a nuisance, price dynamics in network effects are as follows:

- Advertising price falls with a rise in $\theta:\left(\frac{\partial p_{1}^{*}}{\partial \theta}<0\right)$

- Advertising price falls with a rise in $\gamma:\left(\frac{\partial p_{1}^{*}}{\partial \gamma}>0\right)$

Proof. See appendix 9.7.

We find that in the case of an increase in advertising disutility the intuition is similar as in the benchmark model. This is because an increase in $\gamma$ creates a disutility on consumers which puts competitive pressure on platforms to reduce advertisement intensity. The more interesting result is the fall in prices with an increase in $\theta$. In the current subsection, consumers create negative externalities due to their presence on other consumers on a platform. Therefore, platforms seek to discourage too many consumers from joining a platform. They would encourage the marginal consumer to migrate to the rival and create a negative externality on the rival. A unilateral decrease in advertising price at a platform increases advertisement intensity at the platform. This makes the marginal consumer worse-off and migrate to the rival. Similar to the benchmark case but not quiet similar, the total value of the consumer on platform is sum of the positive value the consumer creates on the advertising side and the negative impact they create on other consumers.

\subsubsection{Consumer congestion with positive cross-network benefits}

In this case, consumers are positively impacted by cross-network effects $(\gamma<0)$ from the advertisers and negatively impacted by the congestion other consumers create on a platform. In the following proposition, we provide some insights on how prices react to a change in network effects.

Proposition 10. In a market with consumer congestion $\left(g_{1}=g_{2}=-1\right)$ and advertisements positively valued by consumers (i.e. $\gamma<0$ ), price dynamics in network effects are as follows:

- Advertising price falls with a rise in $\theta:\left(\frac{\partial p_{1}^{*}}{\partial \theta}>0\right)$

\footnotetext{
${ }^{37}$ This externality can also be a proxy for competition between agents on that platform. An increase in $\theta$ would imply increased competition.
} 
- Advertising price falls with a rise in $|\gamma|:\left(\frac{\partial p_{1}^{*}}{\partial \gamma}<0\right)$

The proof for the above is straightforward and therefore omitted. ${ }^{38}$ The above results provide an insight on how equilibrium prices behave when consumers value positively advertisements (or interaction with agents on the other side) while creating a negative externality on other consumers. We find that an increase in consumer congestion externality leads to an increase in advertising price. The intuition for this is similar to its counterpart in the previous subsection with $\gamma>0$. Since $\theta$ is negative, a platform seeks to steer away the marginal consumer to the rival platform. The platform does so by increasing its advertising price, thereby, reducing consumer valued advertising on a platform. This reduces the relative value of a platform for the marginal consumer.

An increase in $|\gamma|$ leads to an increase in consumer utility enhancing advertisements. The intuition for this result is the same as in the literature (see Armstrong (2006)) on two sided markets with positive cross-network externalities. An increase in consumer valuation of the other side increases competition for the other side and thereby reducing the price to increase the presence of the advertisements.

\subsubsection{Discussion on consumer welfare: The failure of competition}

In the setting where consumers exert a congestion externality on one another, we find that competition leads to consumers being doubly hurt. This is the case regardless of whether consumers find advertisement a nuisance $(\gamma>0)$ or the case when consumers find advertisement valuable $(\gamma<0)$. In both these cases, competition acts against consumers and hurts them. We highlight a unique case where competition fails to protect the interest of consumers and hurts them overall. Media see-saws often imply an increase in welfare of one side of the market while the other side loss and the overall impact on welfare might not be clear. However, we find that in a setting where consumers value positively the presence of advertisements, both consumers and advertisers are worse off due to competition with an increase in consumer nuisance. We summarize the results in the proposition below and discuss in detail below.

Proposition 11. When consumers create congestion externality on each other, $\left(g_{1}=g_{2}=-1\right)$, an increase in consumer congestion externality

- when $\gamma \geq 0$, leads to a decrease in consumer surplus and increases advertiser surplus.

- when $\gamma<0$, leads to a fall in both consumer surplus and advertising surplus.

We provide the intuition for these results below.

Case: Consumers find advertisements a nuisance $(\gamma>0)$ In the case, an increase in $\theta$ or consumer congestion leads to further loss in consumer welfare due to increased advertisement. An increased advertising intensity on a platform discourages consumer affiliation with a platform. However, competition leads to increase in advertising intensity with an increase in consumer congestion. In the current setting where consumers create a negative externality on each consumers experience increased negative externality due to the presence of other consumers. This is further compounded by the increase in advertising intensity on platforms due

\footnotetext{
${ }^{38} \mathrm{~A}$ curious reader could use the expressions in appendix 9.7 and make the appropriate changes to obtain the results.
} 
to competition to steer away the marginal consumer to the rival. As a result, advertisers are positively impacted but consumers are hurt doubly. This provides a clear example of how competition might fail to protect consumer interests and instead be detrimental to them. However, one might dispute the total impact on welfare as welfare of advertiser surplus increases.

Case: Consumers value advertisements positively $(\gamma<0)$ In this case, an increase in $\theta$ or consumer congestion leads to further loss in consumer welfare due to a decrease in consumer enhancing advertisements. This is because a platform seeks to discourage the marginal consumer affiliating with the platform. It does so by increasing the advertisement prices and reducing consumer utility by decreasing the mass of positively valued advertisements on the platform. This makes joining that platform less attractive relative to the rival for the marginal consumer. The rival also responds similarly and increases prices. We find that on equilibrium, an consumers are worse-off due to increased negative value from the presence of other consumers as well as lower mass of active advertisers on a platform that increase consumer valuation. In this setting, both consumers and advertisers are hurt doubly with an increase in consumer congestion. Here, there does not exist any Media See saw. This result is due to the competitive pressure platforms exert on each other to increase advertising prices. Here, clearly the consumer surplus, advertising surplus and overall industry surplus is lowered. This is the worst case scenario where competition fails spectacularly and hurts all players in the market. It is our understanding that in this case policy makers must pro-actively intervene to correct this competitive anomaly.

The case for a Monopoly The results in this subsection provide evidence that competition between firms, in markets where the price to consumers is zero, actually leads to a detrimental effect on consumer welfare. This is more so in the case when consumers value positively the other side. This new counterintuitive behavior of competition must be taken into account by anti-trust authorities during merger proceedings. Platforms with consumer congestion present a unique case where we suggest that a monopoly be consumer welfare enhancing. When consumers derive utility from the presence of the other side (advertisers) then a merger to a monopoly between two zero pricing platforms is expected to be consumer surplus, advertising surplus and platform profit enhancing. In such setting, anti-trust authorities should be more pliable to a merger that reduces competition and strongly consider the positive effects of such a merger on all the parties.

\section{Conclusions}

In recent times, large online platforms such as Google and Facebook have emerged that are often indispensable to consumers. They offer "free" consumer access to platform services while charging advertisers for access to consumers. These platforms are very large and yet do not set a (direct) price to consumers. This creates a regulatory grey area as anti-trust authorities are unsure how to assess competition between such platforms. In this paper, we tried to fill this gap by providing insights on the mechanics of comeptition between firms that compete for consumers and earn through advertising revenues. We show that as consumer side externalities (negative advertising externality and same-side externality) rise the intensity of advertisements on a platform falls. This is because these firms compete for consumers by reducing advertising 
intensity. We then look at how a merger might impact competition. We show that postmerger platforms do not care about consumer utility and their incentives are aligned with the advertising side. This creates a harm to consumers even in a setting where consumer facing price is zero. This is because the harm incident on the consumer is implicit through increased advertising. We find that platforms might use strategies to increase advertising side profits and this could be to the detriment of consumers. Post-merger consumers are vulnerable to exploitation by platforms to increase profits in favor of the advertising side. We also discuss a few theories of harm associated with merger and the associated remedies that include advertising caps and data extraction limits.

We also look at multiple extensions to the benchmark model. Firstly, we look at multi-homing consumers as this setting provides insights on a monopolist platform with elastic demand and provide insights on the pricing strategy of platforms. Next, we look at the case when consumers experience congestion externalities where there dislike the presence of other consumers. In this setting, competition between platforms acts against consumer interest. This result is compounded in a setting where consumers value the presence of advertising (content) side while presenting a congestion externality on each other. Competition negatively impacts consumers as well as content providers (which are positively valued by consumers). Competition leads to a clear loss in welfare.

This paper could be extended to look at the interesting case when platforms are able to discriminate between consumers in terms of advertising intensity. This extension might even lead to increased competition between the platforms as in the standard price discrimination literature. However, the two-sidedness of the model will reveal new insights.

\section{References}

Ambrus, A., Calvano, E. \& Reisinger, M. (2016), "Either or both competition: A" two-sided" theory of advertising with overlapping viewerships', American Economic Journal: Microeconomics 8(3), 189-222.

Anderson, S. P., Foros, Ø. \& Kind, H. J. (2018), 'Competition for advertisers and for viewers in media markets', The Economic Journal 128(608), 34-54.

Anderson, S. P. \& Gabszewicz, J. J. (2006), 'The media and advertising: a tale of two-sided markets', Handbook of the Economics of Art and Culture 1, 567-614.

Anderson, S. P. \& Jullien, B. (2015), The advertising-financed business model in two-sided media markets, in 'Handbook of media economics', Vol. 1, Elsevier, pp. 41-90.

Anderson, S. P. \& Peitz, M. (2020), 'Media see-saws: Winners and losers in platform markets', Journal of Economic Theory p. 104990.

Angelini, F., Castellani, M. \& Zirulia, L. (2019), 'Seller competition and platform investment in two-sided markets'.

Argentesi, E., Buccirossi, P., Calvano, E., Duso, T., Marrazzio, A. \& Nava, S. (2019), 'Ex-post assessment of merger control decisions in digital markets', Document prepared by Lear for the Competition and Markets Authority . 
Argentesi, E., Buccirossi, P., Calvano, E., Duso, T., Marrazzo, A. \& Nava, S. (2019), 'Merger policy in digital markets: An ex-post assessment'.

Armstrong, M. (2006), 'Competition in two-sided markets', The RAND Journal of Economics 37(3), 668-691.

Athey, S., Calvano, E. \& Gans, J. S. (2016), 'The impact of consumer multi-homing on advertising markets and media competition', Management Science 64(4), 1574-1590.

Bakos, Y. \& Halaburda, H. (2019), 'Platform competition with multihoming on both sides: Subsidize or not?', Available at SSRN 3468457.

Beebe, J. H. (1977), 'Institutional structure and program choices in television markets', The Quarterly Journal of Economics 91(1), 15-37.

Belleflamme, P. \& Peitz, M. (2019a), 'Managing competition on a two-sided platform', Journal of Economics \& Management Strategy 28(1), 5-22.

Belleflamme, P. \& Peitz, M. (2019b), 'Platform competition: Who benefits from multihoming?', International Journal of Industrial Organization 64, 1-26.

Biglaiser, G., Calvano, E. \& Crémer, J. (2019), 'Incumbency advantage and its value', Journal of Economics \& Management Strategy 28(1), 41-48.

Britainthinks (2018), 'Control, alt or delete? consumer research on attitudes to data collection and use', Which? POLICY RESEARCH REPORT, June 2018.

Brynjolfsson, E., Collis, A. \& Eggers, F. (2019), 'Using massive online choice experiments to measure changes in well-being', Proceedings of the National Academy of Sciences 116(15), 7250-7255.

Bundeskartellamt (2019), 'Bundeskartellamt prohibits facebook from combining user data from different sources', Press release .

URL: https://www.bundeskartellamt.de/SharedDocs/Meldung/EN/Pressemitteilungen/2019/0\% $2_{2} 019_{F}$

Calvano, E. \& Polo, M. (2019), 'Strategic differentiation by business models: Free-to-air and pay-tv', Economic Journal. Forthcoming .

Calvano, E. \& Polo, M. (2020), 'Strategic differentiation by business models: Free-to-air and pay-tv', The Economic Journal 130(625), 50-64.

Carroni, E., Madio, L. \& Shekhar, S. (2019), 'Superstars in two-sided markets: exclusives or not?', Available at SSRN 32437r7y.

Choi, J. P. (2010), 'Tying in two-sided markets with multi-homing', The Journal of Industrial Economics 58(3), 607-626.

Choi, J. P., Jullien, B. \& Lefouili, Y. (2017), 'Tying in two-sided markets with multi-homing: Corrigendum and comment', The Journal of Industrial Economics 65(4), 872-886.

Crampes, C., Haritchabalet, C. \& Jullien, B. (2009), 'Advertising, competition and entry in media industries', The Journal of Industrial Economics 57(1), 7-31. 
D'Annunzio, A. \& Russo, A. (2019), 'Ad networks, consumer tracking, and privacy', Management Science, Forthcoming .

Digital Platforms Inquiry: Final Report, 2019 (2019).

EC Case M.8124-Microsoft/LinkedIn. European Commission Decision C(2016)8404, 2016 (2019).

Esayas, S. (2018), 'Privacy as a non-price competition parameter: Theories of harm in mergers', University of Oslo Faculty of Law Research Paper (2018-26).

Evans, D. S. (2011), 'Antitrust economics of free', Competition Policy International, Spring .

Ex-post Assessment of Merger Control Decisions in Digital Markets, 2019 (n.d.).

URL: https://assets.publishing.service.gov.uk/government/uploads/system/uploads/attachment data $/$ fi

Gautier, A. \& Lamesch, J. (2020), 'Mergers in the digital economy'.

Huang, J., Reiley, D. \& Riabov, N. (2018), 'Measuring consumer sensitivity to audio advertising: A field experiment on pandora internet radio', Available at SSRN 3166676 .

Motta, M. \& Peitz, M. (2020), 'Big tech mergers'.

OECD (2018a), 'Quality considerations in digital zero-price markets', OECD JT03437005, 146.

URL: http://www.oecd.org/officialdocuments/publicdisplaydocumentpdf/?cote $=D S T I / C P(2018) 12 / F I N$

OECD (2018b), 'Summary of roundtable on advertising', OECD JT03434988, 1-46.

URL: http://www.oecd.org/officialdocuments/publicdisplaydocumentpdf/?cote=DSTI/CP(2018)12/FIN

Online platforms and digital advertising Market study: interim report, 2019 (2019).

Prat, A. \& Valletti, T. M. (2019), 'Attention oligopoly', Available at SSRN 3197930 .

Reyna, A. (2018), 'The psychology of privacy-what can behavioral economic contribute to competition in digital markets?', International Data Privacy Law 8(3), 240-252.

Rochet, J.-C. \& Tirole, J. (2003), 'Platform competition in two-sided markets', Journal of the European Economic Association 1(4), 990-1029.

Rochet, J.-C. \& Tirole, J. (2006), 'Two-sided markets: a progress report', The RAND Journal of Economics 37(3), 645-667.

Scott Morton, F., Bouvier, P., Ezrachi, A., Jullien, B., Katz, R., Kimmelman, G., Melamed, A. \& Morgenstern, J. (2019), 'Committee for the study of digital platforms: Market structure and antitrust subcommittee-report', Chicago: Stigler Center for the Study of the Economy and the State, University of Chicago Booth School of Business .

Spence, M. \& Owen, B. (1977), 'Television programming, monopolistic competition, and welfare', The Quarterly Journal of Economics pp. 103-126.

Steiner, P. O. (1952), 'Program patterns and preferences, and the workability of competition in radio broadcasting', The Quarterly Journal of Economics 66(2), 194-223. 
Stucke, M. E. \& Grunes, A. P. (2015), 'Debunking the myths over big data and antitrust', CPI Antitrust Chronicle, May .

Waehrer, K. (2016), 'Online services and the analysis of competitive merger effects in privacy protections and other quality dimensions', Available at SSRN 2701927.

Wilbur, K. C. (2008), 'A two-sided, empirical model of television advertising and viewing markets', Marketing science 27(3), 356-378.

\section{Appendix}

\subsection{Proof of Lemma 1}

Proof. The derivative of $\frac{\partial A_{1}\left(g_{1}, g_{2}\right)}{\partial p_{1}}$

$$
\begin{gathered}
\frac{\partial A_{1}\left(g_{1}, g_{2}\right)}{\partial p_{1}}=\lambda\left(k_{1}\right)\left[\phi \frac{\partial D_{1}\left(g_{1}, g_{2}\right)}{\partial p_{1}}-1\right] \\
\frac{\partial A_{2}\left(g_{2}, g_{1}\right)}{\partial p_{1}}=\lambda\left(k_{2}\right)\left[\phi \frac{\partial D_{2}\left(g_{2}, g_{1}\right)}{\partial p_{1}}\right]=-\lambda\left(k_{2}\right)\left[\phi \frac{\partial D_{1}\left(g_{1}, g_{2}\right)}{\partial p_{1}}\right] \\
\frac{\partial D_{1}\left(g_{1}, g_{2}\right)}{\partial p_{1}}=f\left(s^{*}\right)\left[\theta\left(g_{1} \frac{\partial D_{1}\left(g_{1}, g_{2}\right)}{\partial p_{1}}-g_{2} \frac{\partial D_{2}\left(g_{1}, g_{2}\right)}{\partial p_{1}}\right)-\gamma\left[\frac{\partial A_{1}\left(g_{1}, g_{2}\right)}{\partial p_{1}}-\frac{\partial A_{2}\left(g_{2}, g_{1}\right)}{\partial p_{1}}\right]\right.
\end{gathered}
$$

substituting $\frac{\partial A_{1}\left(g_{1}, g_{2}\right)}{\partial p_{1}}$ and $\frac{\partial A_{2}\left(g_{2}, g_{1}\right)}{\partial p_{1}}$ into $\frac{\partial D_{1}\left(g_{1}, g_{2}\right)}{\partial p_{1}}$ and simplifying we get

$$
\frac{\partial D_{1}\left(g_{1}, g_{2}\right)}{\partial p_{1}}=f\left(s^{*}\right)\left[\frac{\partial D_{1}\left(g_{1}, g_{2}\right)}{\partial p_{1}}\left[\theta\left(g_{1}+g_{2}\right)-\gamma \phi\left(\lambda\left(k_{1}\right)+\lambda\left(k_{2}\right)\right)\right]+\gamma \lambda\left(k_{1}\right)\right]
$$

solving for $\frac{\partial D_{1}}{\partial p_{1}}$, we get

$$
\frac{\partial D_{1}}{\partial p_{1}}=\frac{f\left(s^{*}\right) \gamma \lambda\left(k_{1}\right)}{1-f\left(s^{*}\right)\left(\theta\left(g_{1}+g_{2}\right)-\gamma \phi\left(\lambda\left(k_{1}\right)+\lambda\left(k_{2}\right)\right)\right)}>0
$$

substituting, this into $\frac{\partial A_{1}}{\partial p_{1}}$, we get

$$
\frac{\partial A_{1}}{\partial p_{1}}=\frac{\lambda\left(k_{1}\right)\left[f\left(s^{*}\right)\left(\theta\left(g_{1}+g_{2}\right)-\gamma \phi \lambda\left(k_{2}\right)\right)-1\right]}{1-f\left(s^{*}\right)\left(\theta\left(g_{1}+g_{2}\right)-\gamma \phi\left(\lambda\left(k_{1}\right)+\lambda\left(k_{2}\right)\right)\right)}<0
$$

Under a symmetric equilibrium where $g_{1}=g_{2}=g$, we have $s^{*}=0, k^{*}=\phi / 2-p^{*}$, we get

$$
\frac{\partial A_{1}}{\partial p_{1}}=\frac{\lambda\left(k^{*}\right)\left[f\left(s^{*}\right)\left(2 g \cdot \theta-\gamma \phi \lambda\left(k^{*}\right)\right)-1\right]}{1-2 f\left(s^{*}\right)\left(g \cdot \theta-\gamma \phi \lambda\left(k^{*}\right)\right)}<0
$$




\subsection{Proof of Lemma 2}

Proof. For the case when $g_{1}=g_{2}=0$, we have that

$$
\frac{\partial D_{1}}{\partial p_{1}}=\frac{f\left(s^{*}\right) \gamma \lambda\left(k_{1}\right)}{1+f\left(s^{*}\right) \gamma \phi\left(\lambda\left(k_{1}\right)+\lambda\left(k_{2}\right)\right)}>0
$$

substituting, this into $\frac{\partial A_{1}}{\partial p_{1}}$, we get

$$
\frac{\partial A_{1}}{\partial p_{1}}=\frac{-\lambda\left(k_{1}\right)\left[f\left(s^{*}\right) \gamma \phi \lambda\left(k_{2}\right)+1\right]}{1+f\left(s^{*}\right) \gamma \phi\left(\lambda\left(k_{1}\right)+\lambda\left(k_{2}\right)\right)}<0
$$

Under a symmetric equilibrium $s^{*}=0, k^{*}=\phi / 2-p^{*}$, we get

$$
\frac{\partial A_{1}}{\partial p_{1}}=\frac{-\lambda\left(k^{*}\right)\left[f\left(s^{*}\right) \gamma \phi \lambda\left(k^{*}\right)+1\right]}{1+2 f\left(s^{*}\right) \gamma \phi \lambda\left(k^{*}\right)}
$$

We then substitute the above expression into the first order condition to get an implicit functions that characterizes the equilibrium prices.

\subsection{Proof of Proposition 1}

Proof. In the following, we provide the comparative static with respect to $\phi$ and $\gamma$.

Using implicit function theorem, we obtain the comparative static with respect to a parameter $\mu \in\{\phi, \gamma\}$ as

$$
\frac{\partial p^{*}}{\partial \mu}=\frac{\frac{\partial^{2} \Pi^{*}}{\partial p_{1} \partial \mu}\left(\frac{\partial^{2} \Pi^{*}}{\partial p_{1} \partial p_{2}}-\frac{\partial^{2} \Pi^{*}}{\partial p^{2}}\right)}{\left(\frac{\partial^{2} \Pi^{*}}{\partial p^{2}}\right)^{2}-\left(\frac{\partial^{2} \Pi_{1}^{*}}{\partial p_{1} \partial p_{2}}\right)^{2}}
$$

For the above expression, we exploit symmetry of the model and simplify. It is easy to see that since $\left|\frac{\partial^{2} \Pi_{1}^{*}}{\partial p^{2}}\right|>\left|\frac{\partial^{2} \Pi_{1}^{*}}{\partial p_{1} \partial p_{2}}\right|$, the sign of $\frac{\partial p^{*}}{\partial \mu}$ follows the sign of $\frac{\partial^{2} \Pi^{*}}{\partial p_{1} \partial \mu}$ for $\mu \in\{\gamma\}$. Thereafter, we only look at the direct effect of a parameter to prove the sign of the prices.

To show $\frac{\delta p^{*}}{\delta \gamma}>0$

$$
\begin{aligned}
\frac{\partial^{2} \Pi_{1}^{*}}{\partial p_{1} \partial \gamma} & =\underbrace{\frac{\partial A_{1}^{*}}{\partial \gamma}}_{=0}+p_{1}^{*} \frac{\partial^{2} A_{1}}{\partial p_{1} \partial \gamma} . \\
\frac{\partial A_{1}}{\partial \gamma} & =\lambda\left(k^{*}\right)\left[\phi \frac{\partial^{2} D_{1}}{\partial p_{1} \partial \gamma}\right]
\end{aligned}
$$

The simplified expression for $\frac{\partial^{2} D_{1}}{\partial p_{1} \partial \gamma}$ is as follows

$$
\frac{\partial^{2} D_{1}}{\partial p_{1} \partial \gamma}=\frac{f\left(s^{*}\right) \lambda(k)}{\left(1+f\left(s^{*}\right) \gamma \phi\left(\lambda\left(k_{1}\right)+\lambda\left(k_{2}\right)\right)\right)^{2}}>0
$$




\subsection{Proof of Lemma 3}

Proof. For the case when $g_{1}=g_{2}=1$, we get

$$
\frac{\partial D_{1}}{\partial p_{1}}=f\left(s^{*}\right)\left[\frac{\partial D_{1}}{\partial p_{1}}\left[2 \theta-\gamma \phi\left(\lambda\left(k_{1}\right)+\lambda\left(k_{2}\right)\right)\right]+\gamma \lambda\left(k_{1}\right)\right]
$$

solving for $\frac{\partial D_{1}}{\partial p_{1}}$, we get

$$
\frac{\partial D_{1}}{\partial p_{1}}=\frac{f\left(s^{*}\right) \gamma \lambda\left(k_{1}\right)}{1-f\left(s^{*}\right)\left(2 \theta-\gamma \phi\left(\lambda\left(k_{1}\right)+\lambda\left(k_{2}\right)\right)\right)}>0
$$

substituting, this into $\frac{\partial A_{1}}{\partial p_{1}}$, we get

$$
\frac{\partial A_{1}}{\partial p_{1}}=\frac{\lambda\left(k_{1}\right)\left[f\left(s^{*}\right)\left(2 \theta-\gamma \phi \lambda\left(k_{2}\right)\right)-1\right]}{1-f\left(s^{*}\right)\left(2 \theta-\gamma \phi\left(\lambda\left(k_{1}\right)+\lambda\left(k_{2}\right)\right)\right)}<0
$$

Under a symmetric equilibrium $s^{*}=0, k^{*}=\phi / 2-p^{*}$, we get

$$
\frac{\partial A_{1}}{\partial p_{1}}=\frac{\lambda\left(k^{*}\right)\left[f\left(s^{*}\right)\left(2 \theta-\gamma \phi \lambda\left(k_{2}\right)\right)-1\right]}{1-2 f\left(s^{*}\right)\left(\theta-\gamma \phi \lambda\left(k^{*}\right)\right)}<0
$$

\subsection{Proof of Proposition 2}

Proof. In the following, we provide the comparative static with respect to $\theta$ and $\gamma$.

Using implicit function theorem, we obtain the comparative static with respect to a parameter $\mu \in\{\phi, \gamma, \theta\}$ as

$$
\frac{\partial p^{*}}{\partial \mu}=\frac{\frac{\partial^{2} \Pi^{*}}{\partial p_{1} \partial \mu}\left(\frac{\partial^{2} \Pi^{*}}{\partial p_{1} \partial p_{2}}-\frac{\partial^{2} \Pi^{*}}{\partial p^{2}}\right)}{\left(\frac{\partial^{2} \Pi^{*}}{\partial p^{2}}\right)^{2}-\left(\frac{\partial^{2} \Pi_{1}^{*}}{\partial p_{1} \partial p_{2}}\right)^{2}}
$$

For the above expression, we exploit symmetry of the model and simplify. It is easy to see that since $\left|\frac{\partial^{2} \Pi_{1}^{*}}{\partial p^{2}}\right|>\left|\frac{\partial^{2} \Pi_{1}^{*}}{\partial p_{1} \partial p_{2}}\right|$, the sign of $\frac{\partial p^{*}}{\partial \mu}$ follows the sign of $\frac{\partial^{2} \Pi^{*}}{\partial p_{1} \partial \mu}$ for $\mu \in\{\theta, \gamma\}$. Thereafter, we only look at the direct effect of a parameter to prove the sign of the prices.

The direct effect of a parameter on prices is given as

$$
\frac{\partial^{2} \Pi_{1}^{*}}{\partial p_{1} \partial \mu}=\underbrace{\frac{\partial A_{1}^{*}}{\partial \mu}}_{=0}+p_{1}^{*} \frac{\partial^{2} A_{1}}{\partial p_{1} \partial \mu} .
$$

Thereafter, we focus only on the sign of $\frac{\partial^{2} A_{1}}{\partial p_{1} \partial \mu}$ for $\mu \in\{\theta, \phi, \gamma\}$

To show $\frac{\partial p^{*}}{\partial \boldsymbol{\theta}}>\mathbf{0}$ The simplified expression is given as follows

$$
\frac{\partial^{2} A_{1}^{*}}{\partial p_{1} \partial \theta}=\frac{2 f\left(s^{*}\right)^{2} \lambda\left(k^{*}\right)^{2} \gamma \phi}{\left(1-2 f\left(s^{*}\right)\left(\theta-\gamma \phi \lambda\left(k^{*}\right)\right)^{2}\right.}>0
$$


To show $\frac{\delta p^{*}}{\delta \gamma}>\mathbf{0}$ The simplified expression of $\frac{\partial^{2} A_{1}}{\partial p_{1} \partial \gamma}$ is given as follows

$$
\frac{\partial^{2} A_{1}}{\partial p_{1} \partial \gamma}=\lambda\left(k^{*}\right)\left[\phi \frac{\partial^{2} D_{1}}{\partial p_{1} \partial \gamma}\right]
$$

The simplified expression for $\frac{\partial^{2} D_{1}}{\partial p_{1} \partial \gamma}$ is as follows

$$
\frac{\partial^{2} D_{1}}{\partial p_{1} \partial \gamma}=\frac{f\left(s^{*}\right) \lambda(k)\left(1-2 \theta f\left(s^{*}\right)\right)}{\left(1-2 f\left(s^{*}\right) X\right)^{2}}
$$

where $X=\theta-\gamma \phi \lambda\left(k^{*}\right)$. The above expression is positive for $1>2 \theta f\left(s^{*}\right)$ and negative otherwise.

\subsection{Proof of Proposition 5}

Proof. In the following, we provide the comparative static with respect to $\theta$ and $\gamma$ for the cases $g_{1}=g_{2} \in\{0,1\}$.

As in proposition 2 , the sign of $\frac{\partial p^{M *}}{\partial \mu}$ follows the sign of $\frac{\partial^{2} \Pi^{M *}(g, g)}{\partial p_{1} \partial \mu}$ for $\mu \in\{\theta, \gamma\}$. Thereafter, we only look at the direct effect of a parameter to prove the sign of the prices.

The direct effect of a parameter on prices is given as

$$
\frac{\partial^{2} \Pi_{1}^{M, *}(g, g)}{\partial p_{1} \partial \mu}=\frac{\partial A_{1}^{*}}{\partial \mu}+p_{1}^{*}\left(\frac{\partial\left[\frac{\partial A_{1}}{\partial p_{1}}\right]}{\partial \mu}+\frac{\partial\left[\frac{\partial A_{2}}{\partial p_{1}}\right]}{\partial \mu}\right)
$$

for $\mu \in\{\theta, \gamma\}$ and $\frac{\partial A_{1}}{\partial \mu}=0$.

We know that

$$
\begin{gathered}
\frac{\partial A_{1}}{\partial p_{1}}=\lambda\left(k_{1}\right)\left[\phi \frac{\partial D_{1}}{\partial p_{1}}-1\right] \\
\frac{\partial A_{2}}{\partial p_{1}}=-\lambda\left(k_{2}\right)\left[\phi \frac{\partial D_{1}}{\partial p_{1}}\right]
\end{gathered}
$$

From the two expressions above, it is easy to see that $\frac{\partial\left[\frac{\partial A_{1}}{\partial p_{1}}\right]}{\partial \mu}=-\frac{\partial\left[\frac{\partial A_{2}}{\partial p_{1}}\right]}{\partial \mu}$ and this gives us the result that

$$
\frac{\partial^{2} \Pi_{1}^{M, *}(g, g)}{\partial p_{1} \partial \mu}=0
$$

\subsection{Proof of Proposition 10}

Proof. For the case of $g_{1}=g_{2}=-1$, we obtain the following comparative statics.

To show $\frac{\partial p^{*}}{\partial \theta}<0$ The simplified expression is given as follows

$$
\frac{\partial^{2} A_{1}^{*}}{\partial p_{1} \partial \theta}=-\frac{2 f\left(s^{*}\right)^{2} \lambda\left(k^{*}\right)^{2} \gamma \phi}{\left(1-2 f\left(s^{*}\right)\left(\theta-\gamma \phi \lambda\left(k^{*}\right)\right)^{2}\right.}<0
$$


To show $\frac{\delta p^{*}}{\delta \gamma}>\mathbf{0}$ The simplified expression of $\frac{\partial^{2} A_{1}}{\partial p_{1} \partial \gamma}$ is given as follows

$$
\frac{\partial^{2} A_{1}}{\partial p_{1} \partial \gamma}=-\lambda\left(k^{*}\right)\left[\phi \frac{\partial^{2} D_{1}}{\partial p_{1} \partial \gamma}\right]
$$

The simplified expression for $\frac{\partial^{2} D_{1}}{\partial p_{1} \partial \gamma}$ is as follows

$$
\frac{\partial^{2} D_{1}}{\partial p_{1} \partial \gamma}=\frac{f\left(s^{*}\right) \lambda(k)\left(1+2 \theta f\left(s^{*}\right)\right)}{\left(1+2 f\left(s^{*}\right) X\right)^{2}}
$$

where $X:=\theta+\gamma \phi \lambda\left(k^{*}\right)$. The above expression is always positive.

\subsection{Multi-homing consumers}

Proof. The total consumer demand on platform 1 is given by $D_{1}=F\left(s_{2}^{*}\right)$ where $s_{2}^{*}(g)=$ $2\left(v-\gamma A_{1}+\theta g_{1} D_{1}\right)$.

The advertiser demand on platform is then given by $\Lambda\left(k_{i}\right)$ where $k_{i}=\phi * D_{i}-p_{i}$.

The derivative of $\frac{\partial A_{1}}{\partial p_{1}}$

$$
\begin{gathered}
\frac{\partial A_{1}}{\partial p_{1}}=\lambda\left(k_{1}\right)\left[\phi \frac{\partial D_{1}}{\partial p_{1}}-1\right] \\
\frac{\partial D_{1}}{\partial p_{1}}=f\left(s^{*}\right) 2\left[\theta \cdot g \cdot \frac{\partial D_{1}}{\partial p_{1}}-\gamma \frac{\partial A_{1}}{\partial p_{1}}\right]
\end{gathered}
$$

substituting $\frac{\partial A_{1}}{\partial p_{1}}$ into $\frac{\partial D_{1}}{\partial p_{1}}$ and simplifying we get

$$
\frac{\partial D_{1}}{\partial p_{1}}=\frac{2 f\left(s^{*}\right) \gamma \lambda\left(k_{1}\right)}{1-2 f\left(s^{*}\right)\left(\theta \cdot g_{1}-\gamma \phi \lambda\left(k_{1}\right)\right)}>0
$$

substituting, this into $\frac{\partial A_{1}}{\partial p_{1}}$, we get

$$
\frac{\partial A_{1}}{\partial p_{1}}=\frac{\lambda\left(k_{1}\right)\left[2 f\left(s^{*}\right) \theta g_{1}-1\right]}{1-2 f\left(s^{*}\right)\left(\theta \cdot g_{1}-\gamma \phi \lambda\left(k_{1}\right)\right)}<0
$$

The platform sets advertising prices to maximize its profits denoted by

$$
\Pi_{i}=p_{i} * A_{i}
$$

The first order conditions are given as

$$
\frac{\partial \Pi_{i}}{\partial p_{i}}=A_{i}+p_{i} * \frac{\partial A_{i}}{\partial p_{i}}
$$

\section{Comparative statics of the price}

Before we proceed, it is straightforward that the direction of price change with respect to $\mu \in\{\theta, \gamma\}$ will be equal to the direct effect given as

$$
\operatorname{sign}\left(\frac{\partial p_{i}^{*}}{\partial \mu}\right)=\operatorname{sign}\left(\frac{\partial^{2} \Pi_{i}^{*}}{\partial p_{i} \partial \mu}\right) \text { for } \mu \in\{\theta, \gamma\}
$$


The expression for the direct effect is

$$
\frac{\partial^{2} \Pi_{i}^{*}}{\partial p_{i} \partial \mu}=\frac{\partial A_{i}}{\partial \mu}+p_{i}^{*} \frac{\partial^{2} A_{1}}{\partial p_{1} \partial \mu} \text { for } \mu \in\{\theta, \phi\}
$$

We first start with the change of price in $\theta$ :

\section{To show $\frac{\partial p_{1}}{\partial \theta}>0$}

We show the final expression of the components of equation (33). The expression for the first component is

$$
\begin{aligned}
\frac{\partial A_{1}}{\partial \theta} & =\lambda\left(k_{1}\right) \phi \frac{\partial D_{1}}{\partial \theta} \\
& =\lambda\left(k_{1}\right) \phi \frac{2 g \cdot f(s) D_{1}}{1-2 f(s)(g \cdot \theta-\phi \gamma \lambda(k))}>0
\end{aligned}
$$

The expression for the second component is given as follows:.

$$
\frac{\partial^{2} A_{1}}{\partial p_{1} \partial \theta}=\frac{2 \lambda^{2} \gamma \phi \cdot\left[f^{2} \cdot g_{1}+\frac{\partial f}{\partial \theta}\right]-\frac{\partial \lambda(k)}{\partial \theta}\left(2 f(s) \theta g_{1}-1\right)^{2}}{\left[1-2 f(s)\left(g_{1} \cdot \theta-\phi \gamma \lambda(k)\right)\right]^{2}}
$$

We know that $\frac{\partial \lambda(k)}{\partial \theta}=\lambda(k)^{\prime} \phi \frac{\partial D_{1}}{\partial \theta}>0$ The above expression is positive for a large range of distributions including the uniform distribution.

\section{To show $\frac{\partial p_{1}}{\partial \gamma}>0$}

We show the final expression of the components of equation (33). The expression for the first component is

$$
\begin{aligned}
\frac{\partial A_{1}}{\partial \theta} & =\lambda\left(k_{1}\right) \phi \frac{\partial D_{1}}{\partial \gamma} \\
& =\lambda\left(k_{1}\right) \phi \frac{\left(-2 A_{1} f(s)\right)}{1-2 f(s)\left(g_{1} \cdot \theta-\phi \gamma \lambda(k)\right)}<0
\end{aligned}
$$

The expression for the second component is given as follows:.

$$
\begin{aligned}
\frac{\partial^{2} A_{1}}{\partial p_{1} \partial \gamma} & =\lambda\left(k_{1}\right) \phi \frac{\partial D_{1}}{\partial \gamma} \\
& =\frac{\left(1-2 \theta g_{1} f(s)\right)\left[f(s) \lambda^{2} \phi-\left(1-2 \theta g_{1} f(s)\right) \frac{\partial \lambda}{\partial \gamma}\right]+2 \lambda\left(k_{1}\right) \gamma \phi \frac{\partial f(s)}{\partial \gamma}}{\left[1-2 f(s)\left(g_{1} \cdot \theta-\phi \gamma \lambda(k)\right)\right]^{2}}
\end{aligned}
$$

We know that $\frac{\partial \lambda(k)}{\partial \gamma}=\lambda(k)^{\prime} \phi \frac{\partial D_{1}}{\partial \gamma}<0,1-2 \theta g_{1} f(s)>0$. The above expression is positive for a large range of distributions including the uniform distribution. 


\subsection{Proof of Proposition}

Proof. In the following, we fist provide the comparative static of price with respect to $\phi$ and then for advertising demand $A_{i}$ for the cases $g_{1}=g_{2} \in\{0,1\}$.

To show $\frac{\partial p_{i}}{\partial \phi}>\mathbf{0}$ As in proposition 2, the sign of $\frac{\partial p^{M *}}{\partial \phi}$ follows the sign of $\frac{\partial^{2} \Pi^{M *}(g, g)}{\partial p_{1} \partial \phi}$. Thereafter, we only look at the direct effect of a parameter to prove the sign of the prices.

The direct effect of a parameter on prices is given as

$$
\frac{\partial^{2} \Pi_{1}^{M, *}(g, g)}{\partial p_{1} \partial \phi}=\frac{\partial A_{1}}{\partial \phi}+p_{1}^{*}\left(\frac{\partial\left[\frac{\partial A_{1}}{\partial p_{1}}\right]}{\partial \mu}+\frac{\partial\left[\frac{\partial A_{2}}{\partial p_{1}}\right]}{\partial \mu}\right)
$$

for $\mu \in\{\theta, \gamma\}$ and $\frac{\partial A_{1}}{\partial \mu}>0$.

We know that

$$
\begin{gathered}
\frac{\partial A_{1}}{\partial p_{1}}=\lambda\left(k_{1}\right)\left[\phi \frac{\partial D_{1}}{\partial p_{1}}-1\right] \\
\frac{\partial A_{2}}{\partial p_{1}}=-\lambda\left(k_{2}\right)\left[\phi \frac{\partial D_{1}}{\partial p_{1}}\right]
\end{gathered}
$$

From the two expressions above, it is easy to see that $\frac{\partial\left[\frac{\partial A_{1}}{\partial p_{1}}\right]}{\partial \phi}=-\frac{\partial\left[\frac{\partial A_{2}}{\partial p_{1}}\right]}{\partial \phi}$ and this gives us the result that

$$
\frac{\partial^{2} \Pi_{1}^{M, *}(g, g)}{\partial p_{1} \partial \phi}=\frac{\partial A_{1}}{\partial \phi}=D_{1}>0
$$

Thus, the sign of $\frac{\partial p_{i}}{\partial \phi}>0$.

To show $\frac{\partial A_{i}}{\partial \phi}>0$ The expression of the above is

$$
\frac{\partial A_{i}}{\partial \phi}=\lambda\left(k_{i}\right)\left(D_{i}+\phi \frac{\partial D_{i}}{\partial \phi}-\frac{\partial p_{i}}{\partial \phi}\right)
$$

In the above,

$$
\frac{\partial D_{i}^{*}}{\partial \phi}=0
$$

and $D_{1}>\frac{\partial p_{1}}{\partial \phi}$. [Show later $]$

\subsection{A simple Hotelling set-up}

\subsubsection{Competing platforms}

Consumers are uniformly distributed along a hotelling preference line with utility from joining platform 1 is denoted by

$$
u_{1}=v+g_{1} \cdot \mathbf{E} D_{1}-\gamma A_{1}-t * x
$$

and from joining platform 2 is denoted by

$$
u_{2}=v+g_{2} \cdot \mathbf{E} D_{2}-\gamma A_{2}-t *(1-x)
$$


where $\mathbf{E} D_{1}$ and $\mathbf{E} D_{2}$ are the consumer beliefs on total consumer mass on a platform.

The advertisers are also distributed uniformly according to their type $k$. The utility of an advertiser of type $k$ of joining a platform $i$ is

$$
v_{i}=\phi * D_{i}-p_{i}-k
$$

Advertisers join a platform if $v_{i}>0$ implying that $A_{i}=\phi * D_{i}-p_{i}$.

The indifferent consumer is then given as $x^{*}=\frac{1}{2}+\frac{\theta\left(g_{1} \cdot \mathbf{E} D_{1}-g 2 \cdot \mathbf{E} D_{2}\right)-\gamma\left(A_{1}-A_{2}\right)}{2 t}$ which results in $D_{1}=x^{*}$ and $D_{2}=1-x^{*}$. Solving the demands simultaneously and utilising the fulfilled expectations equilibrium concept, we obtain the following demand functions in terms of prices.

$$
\begin{aligned}
A_{i}\left(g_{i}, g_{j}\right) & =\frac{\phi\left(t-p_{j} * \phi-g_{j} \theta+\gamma \phi\right)-p_{i}\left(2 t-\theta\left(g_{1}+g_{2}\right)+\gamma \phi\right)}{2 t-\theta\left(g_{1}+g_{2}\right)+2 \gamma \phi} \\
D_{i}\left(g_{i}, g_{j}\right) & =\frac{t-g_{j} \cdot \theta+\gamma\left(p_{i}-p_{j}+\phi\right)}{2 t-\left(g_{i}+g_{j}\right) \theta+2 \gamma \phi}
\end{aligned}
$$

The platforms set prices to maximize profits given by

$$
\max _{p_{i}} \Pi_{i}=p_{i} A_{i}
$$

The equilibrium price set by a platform $i$ is given as

$$
p_{i}^{*}\left(g_{i}, g_{j}\right)=\phi \frac{2\left(t-g_{j} \cdot \theta\right)\left(2 t-\left(g_{i}+g_{j}\right) \theta\right)+\gamma \phi\left(5 t-\left(g_{i}+4 g_{j}\right) \theta+\gamma \phi\right)}{\left(4 t-2\left(g_{i}+g_{j}\right) \theta+\gamma \phi\right)\left(4 t-2\left(g_{i}+g_{j}\right) \theta+3 \gamma \phi\right)}
$$

The resulting consumer and advertiser demand for a platform is as follows.

$$
\begin{aligned}
A_{i}^{*}\left(g_{i}, g_{j}\right) & =\phi \frac{\left(2 t-\left(g_{i}+g_{j}\right) \theta+\gamma \phi\right)\left(2\left(t-g_{j} \cdot \theta\right)\left(2 t-\left(g_{i}+g_{j}\right) \theta\right)+\gamma \phi\left(5 t-\left(g_{i}+4 g_{j}\right) \theta+\gamma \phi\right)\right.}{\left(4 t-2\left(g_{i}+g_{j}\right) \theta+\gamma \phi\right)\left(4 t-2\left(g_{i}+g_{j}\right) \theta+3 \gamma \phi\right)} \\
D_{i}^{*}\left(g_{i}, g_{j}\right) & =\frac{1}{2}\left(1+\theta\left(g_{i}-g_{j}\right) \frac{4 t-2 \theta\left(g_{i}+g_{j}\right)+3 \gamma \phi}{\left.\left(2 t-\left(g_{i}+g_{j}\right) \theta+2 \gamma \phi\right)\left(4 t-2\left(g_{i}+g_{j}\right) \theta+\gamma \phi\right)\right)}\right)
\end{aligned}
$$

The resulting equilibrium profits of a platform $i$ is then given by

$$
\Pi_{i}^{*}=\frac{\phi^{2}\left(2 t-\left(g_{i}+g_{j}\right) \theta+\gamma \phi\right)\left(2\left(t-g_{j} \cdot \theta\right)\left(2 t-\left(g_{i}+g_{j}\right) \theta\right)+\gamma \phi\left(5 t-\left(g_{i}+4 g_{j}\right) \theta+\gamma \phi\right)\right)^{2}}{\left(4 t-2\left(g_{i}+g_{j}\right) \theta+\gamma \phi\right)^{2}\left(2 t-\left(g_{i}+g_{j}\right) \theta+2 \gamma \phi\right)\left(4 t-2 \theta\left(g_{i}+g_{j}\right)+3 \gamma \phi\right)^{2}}
$$

Using the above, we can easily characterize the prices for the case when platform competition is between two standard advertising funded platforms $\left(g_{1}=g_{2}=0\right)$, two social media platforms $\left(g_{1}=g_{2}=1\right)$ and competition between a social media platform and a standard platform $\left(g_{1}=1\right.$ and $\left.g_{2}=0\right)$.

\subsubsection{Competition between standard platforms}

This is the case when $g_{1}=g_{2}=0$. We focus on the symmetric equilibrium which is described below. 


$$
p^{*}(0,0)=\frac{\phi(\gamma \phi+t)}{3 \gamma \phi+4 t}
$$

The resulting consumer and advertiser demand for a platform is as follows.

$$
\begin{aligned}
& N^{*}(0,0)=\frac{\phi(\gamma \phi+2 t)}{6 \gamma \phi+8 t} \\
& D^{*}(0,0)=\frac{1}{2}
\end{aligned}
$$

The resulting equilibrium profits of a platform $i$ is then given by

$$
\Pi_{i}^{*}(0,0)=\frac{\phi^{2}(\gamma \phi+t)(\gamma \phi+2 t)}{2(3 \gamma \phi+4 t)^{2}}
$$

\subsubsection{Competition between two social media platforms}

This is the case when $g_{1}=g_{2}=1$. We focus on a symmetric equilibrium which is described below.

$$
p^{*}(1,1)=\frac{\phi(\gamma \phi-\theta+t)}{3 \gamma \phi-4 \theta+4 t}
$$

The resulting consumer and advertiser demand for a platform is as follows.

$$
\begin{aligned}
A^{*}(1,1) & =\frac{\phi(\gamma \phi-2 \theta+2 t)}{6 \gamma \phi-8 \theta+8 t} \\
D^{*}(1,1) & =\frac{1}{2}
\end{aligned}
$$

The resulting equilibrium profits of a platform $i$ is then given by

$$
\Pi^{*}(1,1)=\frac{\phi^{2}(\gamma \phi-2 \theta+2 t)(\gamma \phi-\theta+t)}{2(3 \gamma \phi-4 \theta+4 t)^{2}}
$$

\subsubsection{Competition between a standard platform and a social media platform}

This is the case when $g_{1}=1$ and $g_{2}=0$. The equilibrium prices, advertisement demand and consumer demand are asymmetric and given below.

$$
\begin{aligned}
p_{1}^{*}(1,0) & =\frac{\phi\left(\gamma \phi(\gamma \phi-\theta)+4 t^{2}+t(5 \gamma \phi-2 \theta)\right)}{(\gamma \phi-2 \theta+4 t)(3 \gamma \phi-2 \theta+4 t)} \\
p_{2}^{*}(0,1) & =\frac{\phi\left(\gamma^{2} \phi^{2}-4 \gamma \theta \phi+2 \theta^{2}+4 t^{2}+5 \gamma t \phi-6 \theta t\right)}{(\gamma \phi-2 \theta+4 t)(3 \gamma \phi-2 \theta+4 t)}
\end{aligned}
$$


The resulting consumer and advertiser demand for a platform is as follows.

$$
\begin{aligned}
& A_{1}^{*}(1,0)=\frac{\phi(\gamma \phi-\theta+2 t)\left(\gamma \phi(\gamma \phi-\theta)+4 t^{2}+t(5 \gamma \phi-2 \theta)\right)}{(\gamma \phi-2 \theta+4 t)(2 \gamma \phi-\theta+2 t)(3 \gamma \phi-2 \theta+4 t)} \\
& A_{2}^{*}(0,1)=\frac{\phi(\gamma \phi-\theta+2 t)\left(\gamma^{2} \phi^{2}-4 \gamma \theta \phi+2 \theta^{2}+4 t^{2}+5 \gamma t \phi-6 \theta t\right)}{(\gamma \phi-2 \theta+4 t)(2 \gamma \phi-\theta+2 t)(3 \gamma \phi-2 \theta+4 t)} \\
& D_{1}^{*}(1,0)=\frac{1}{6}\left(\theta\left(\frac{1}{2 \gamma \phi-\theta+2 t}+\frac{4}{\gamma \phi-2 \theta+4 t}\right)+3\right)
\end{aligned}
$$

The resulting equilibrium profits of a platform $i$ is then given by

$$
\begin{aligned}
& \Pi_{1}^{*}(1,0)=\frac{\phi^{2}(\gamma \phi-\theta+2 t)\left(\gamma \phi(\gamma \phi-\theta)+4 t^{2}+t(5 \gamma \phi-2 \theta)\right)^{2}}{(\gamma \phi-2 \theta+4 t)^{2}(2 \gamma \phi-\theta+2 t)(3 \gamma \phi-2 \theta+4 t)^{2}} \\
& \Pi_{2}^{*}(0,1)=\frac{\phi^{2}(\gamma \phi-\theta+2 t)\left(\gamma^{2} \phi^{2}-4 \gamma \theta \phi+2 \theta^{2}+4 t^{2}+5 \gamma t \phi-6 \theta t\right)^{2}}{(\gamma \phi-2 \theta+4 t)^{2}(2 \gamma \phi-\theta+2 t)(3 \gamma \phi-2 \theta+4 t)^{2}}
\end{aligned}
$$

We find that the following

$$
\begin{aligned}
p_{1}^{*}(1,0)-p_{2}^{*}(0,1) & =\frac{\theta \phi}{\gamma \phi-2 \theta+4 t} \\
A_{1}^{*}(1,0)-A_{2}^{*}(0,1) & =\frac{\theta \phi(\gamma \phi-\theta+2 t)}{(\gamma \phi-2 \theta+4 t)(2 \gamma \phi-\theta+2 t)}>0 \\
D_{1}^{*}(1,0)-D_{2}^{*}(0,1) & =\frac{\theta \phi(\gamma \phi-\theta+2 t)}{(\gamma \phi-2 \theta+4 t)(2 \gamma \phi-\theta+2 t)}>0
\end{aligned}
$$

\subsubsection{Merger between competing platforms}

In this subsection, we look at the case when there is a merger between platforms. This merger can be between two standard platforms $\left(g_{1}=g_{2}=0\right)$, two social media platforms $\left(g_{1}=g_{2}=1\right)$ or between a social media platform and a standard platform $\left(g_{1}=1\right.$ and $\left.g_{2}=0\right)$. The merged entity sets prices to maximize

$$
\max _{p_{1}, p_{2}} \Pi^{M}\left(g_{1}, g_{2}\right)=p_{1} A_{1}+p_{2} A_{2}
$$

The equilibrium price, advertisement and consumer demand on the merged platform is given as

$$
\begin{aligned}
p_{i}^{M *}\left(g_{i}, g_{2}\right) & =\phi \frac{t-g_{j} \theta}{4 t-2\left(g_{1}+g_{2}\right) \theta} \\
A_{i}^{M *}\left(g_{i}, g_{j}\right) & =\frac{\phi\left(t-g_{j} \theta+\gamma \phi\right)}{4 t-2\left(g_{1}+g_{2}\right) \theta+4 \gamma \phi} \\
D_{i}^{M *}\left(g_{i}, g_{j}\right) & =\frac{t-g_{j} \theta+\gamma \phi \frac{4 t-\left(g_{i}+3 g_{j}\right) \theta}{4 t-2\left(g_{1}+g_{2}\right)}}{2 t-\left(g_{1}+g_{2}\right) \theta+2 \gamma \phi}
\end{aligned}
$$


The corresponding profit of the merged platform is given as

$$
\Pi_{i}^{M *}\left(g_{i}, g_{j}\right)=\frac{\phi^{2}\left(\theta\left(\theta\left(g_{1}^{2}+g_{2}^{2}\right)-\gamma \phi\left(g_{1}+g_{2}\right)\right)-2 \theta t\left(g_{1}+g_{2}\right)+2 t^{2}+2 \gamma t \phi\right)}{4\left(2 t-\theta\left(g_{1}+g_{2}\right)\right)\left(2 \gamma \phi-\theta\left(g_{1}+g_{2}\right)+2 t\right)}
$$

Now, we can easily look at the counterparts when $g_{i}=g_{j} \in\{0,1\}$ and $g_{i} \neq g_{j}$.

\subsubsection{Merger of two competing standard platforms or two social media platforms}

In the case of two standard platforms $g_{1}=g_{2}=g \in\{0,1\}$, the symmetric equilibrium price, advertisement and consumer demand on the merged platform is given as

$$
\begin{aligned}
p^{M *}(g, g) & =\frac{\phi}{4} \\
A^{M *}(g, g) & =\frac{\phi}{4} \\
D^{M *}(g, g) & =1 / 2
\end{aligned}
$$

The corresponding profit is given as

$$
\Pi_{i}^{M *}(g, g)=\frac{\phi^{2}}{8}
$$

The consumer and producer surplus is given as

$$
\begin{aligned}
& C S^{M *}(g, g)=\frac{4 v-\gamma \phi+2 g \cdot \theta-t}{4} \\
& P S^{M *}(g, g)=\frac{\phi^{2}}{16}
\end{aligned}
$$

\subsubsection{Merger of a Social media platform and a standard platform}

In the case of two standard platforms $g_{1}=1$ and $g_{2}=0$, the equilibrium price, advertisement and consumer demands are asymmetric on a platform is given as

$$
\begin{aligned}
p_{1}^{M *}(1,0) & =\frac{t \phi}{4 t-2 \theta} \\
p_{2}^{M *}(0,1) & =\frac{\phi(t-\theta)}{4 t-2 \theta} \\
A_{1}^{M *}(1,0) & =\frac{\phi(\gamma \phi+t)}{4 \gamma \phi-2 \theta+4 t} \\
A_{2}^{M *}(0,1) & =\frac{\phi(\gamma \phi-\theta+t)}{4 \gamma \phi-2 \theta+4 t} \\
D_{1}^{M *}(1,0) & =\frac{-\gamma \theta \phi+4 t^{2}+4 \gamma t \phi-2 \theta t}{2(2 t-\theta)(2 \gamma \phi-\theta+2 t)}
\end{aligned}
$$


and $D_{2}^{M *}(0,1)=1-D_{1}^{M *}(1,0)$. The corresponding profit is given as

$$
\Pi_{i}^{M *}(1,0)=\frac{\phi^{2}\left(-\gamma \theta \phi+\theta^{2}+2 t^{2}+2 \gamma t \phi-2 \theta t\right)}{4(2 t-\theta)(2 \gamma \phi-\theta+2 t)}
$$

The consumer and producer surplus is given as

$$
\begin{aligned}
C S^{M *}(1,0) & =v+\frac{\left(-4 \gamma \phi-\frac{(4 t-\theta)\left(2 \theta^{2}+4 t^{2}-7 \theta t\right)}{(\theta-2 t)^{2}}+\frac{2 \theta^{2}(\theta-3 t)}{(\theta-2 t)(2 \gamma \phi-\theta+2 t)}+\frac{\theta^{2} t}{(-2 \gamma \phi+\theta-2 t)^{2}}\right)}{16} \\
P S^{M *}(1,0) & =\frac{\phi^{2}\left(2 \gamma^{2} \phi^{2}-2 \gamma \theta \phi+\theta^{2}+2 t^{2}+4 \gamma t \phi-2 \theta t\right)}{8(-2 \gamma \phi+\theta-2 t)^{2}}
\end{aligned}
$$

